University of Nebraska - Lincoln

DigitalCommons@University of Nebraska - Lincoln

$9-28-2004$

\title{
Methodology comparison for canopy structure parameters extraction from digital hemispherical photography in boreal forests
}

\author{
Sylvain G. Leblanc \\ Canada Centre for Remote Sensing \\ Jing M. Chen \\ University of Toronto, chenj@geog.utoronto.ca \\ Richard Fernandes \\ Canada Centre for Remote Sensing \\ Donald w. Deering \\ National Aeronautics Space Administration (NASA) \\ Alexis Conley \\ NASA Goddard Space Flight Center
}

Follow this and additional works at: https://digitalcommons.unl.edu/nasapub

Part of the Physical Sciences and Mathematics Commons

Leblanc, Sylvain G.; Chen, Jing M.; Fernandes, Richard; Deering, Donald w.; and Conley, Alexis, "Methodology comparison for canopy structure parameters extraction from digital hemispherical photography in boreal forests" (2004). NASA Publications. 6.

https://digitalcommons.unl.edu/nasapub/6

This Article is brought to you for free and open access by the National Aeronautics and Space Administration at DigitalCommons@University of Nebraska - Lincoln. It has been accepted for inclusion in NASA Publications by an authorized administrator of DigitalCommons@University of Nebraska - Lincoln. 


\title{
Methodology comparison for canopy structure parameters extraction from digital hemispherical photography in boreal forests
}

\author{
Sylvain G. Leblanc ${ }^{\mathrm{a}, *}$, Jing M. Chen ${ }^{\mathrm{b}}$, Richard Fernandes ${ }^{\mathrm{c}, 1}$, \\ Donald W. Deering ${ }^{\mathrm{d}}$, Alexis Conley ${ }^{\mathrm{e}}$ \\ ${ }^{a}$ Natural Resources Canada/Canada Centre for Remote Sensing, 6767 Route de l'aéroport, St-Hubert, Que., Canada J3Y $8 Y 9$ \\ ${ }^{\mathrm{b}}$ Department of Geography and Program in Planning, University of Toronto, 100 George St., \\ Room 5047, Toronto, Ont., Canada M5S $3 G 3$ \\ ${ }^{\mathrm{c}}$ Natural Resources Canada/Canada Centre for Remote Sensing, 588 Booth St., 4th Floor, Ottawa, Ont., Canada K1A 0Y7 \\ ${ }^{\mathrm{d}}$ National Aeronautics Space Administration (NASA), Goddard Space Flight Center, Biospheric Sciences Branch, \\ Mail Code 923, Greenbelt, MD 20771, USA \\ e Science Systems and Applications Inc. (SSAI), NASA Goddard Space Flight Center, Biospheric Sciences Branch, \\ Mail Code 923.4, Greenbelt, MD 20771, USA
}

Received 7 April 2004; accepted 28 September 2004

\begin{abstract}
The retrieval of canopy architectural parameters using off-the-shelf digital cameras with fish-eye lens is investigated. The technique used takes advantage of the sensor's linear response to light of these cameras to improve the estimation of gap fraction using:

(1) the digital numbers of mixed sky-canopy pixels to estimate the within-pixel gap fraction; and

(2) this process is done considering the variation in view zenith angle to take into account the sky radiance distribution and the canopy multiple scattering effects.
\end{abstract}

The foliage element clumping index is retrieved over a wide range of view zenith angles using:

(1) the accumulated gap size distribution theory developed for the TRAC by Chen and Cihlar (1995a);

(2) the Lang and Xiang (1986) finite-length averaging method; and

(3) a method combining the gap size distribution and the Lang and Xiang finite-length methods.

\footnotetext{
* Corresponding author. Tel.: +1 450926 4646; fax: +1 4509264449.

E-mail addresses: Sylvain.Leblanc@CCRS.NRCan.gc.ca (S.G. Leblanc), chenj@geog.utoronto.ca (J.M. Chen), Richard.Fernandes@CCRS.NRCAN.gc.ca (R. Fernandes), Donald.Deering@gsfc.nasa.gov (D.W. Deering), Alexis.Conley@gsfc.nasa.gov (A. Conley).

${ }^{1}$ Tel.: +1 613947 1292; fax: +1 6139471385 .
} 
Using data from Canadian and Russian boreal forests, comparisons of gap fraction, clumping index and plant area index measured with the tracing radiation and architecture of canopies (TRAC) and digital hemispherical photography are presented. Evaluation of the LAI estimated from digital hemispherical photography with allometric LAI of two boreal forest stands suggest that that the clumping index combined method may be more accurate.

(C) 2005 Published by Elsevier B.V.

Keywords: Leaf area index; Canopy architecture; TRAC; Hemispherical photography

\section{Introduction}

The boreal forest covers about one third of the global forested area and can be found in Russia, Canada, Scandinavia and Alaska. This biome type is greatly affected by global warming, as it is limited in its growth, among other reasons, by its short growing season and low solar radiation. To study changes in this biome, remote sensing tools are useful because they provide appropriate spatial extent and access to remote locations. Foliage density, often quantified by the leaf area index (LAI), defined as half the total surface area per unit of horizontal ground area (Chen and Black, 1992a), is a measure that has shown potential for mapping areas using optical space-borne sensors (Running et al., 1989; Myneni et al., 1997; Bicheron and Leroy, 1999; Privette et al., 2002; Chen et al., 2002; Fernandes et al., 2003). However, calibration of global LAI maps requires many more ground truth points than currently available worldwide (e.g. Scurlock et al., 2001; Asner et al., 2003). Fast and accurate extraction of canopy structural parameters is important, as fieldwork is expensive and weather dependant. Several methodologies have been used to measure LAI in vegetation canopies (see Jonckheere et al., 2004; Weiss et al., 2004). Optical sensors are often used to estimate LAI from radiation transmittance through the canopy. The simple, yet effective, Beer-Lambert's law has often been used to model canopy transmittance as:

$P(\theta)=\mathrm{e}^{-G(\theta) \Omega(\theta) L_{\mathrm{t}} / \cos \theta}$

where $\theta$ is the zenith angle, $P(\theta)$ the canopy gap fraction, $G(\theta)$ the projection of unit foliage in the $\theta$ direction, which characterizes the foliage angular distribution (e.g. Warren-Wilson and Reeve, 1959; Norman and Campbell, 1989; Welles and Norman, 1991); $\Omega(\theta)$, the (element) clumping index (Nilson, 1971 ), is a parameter determined by the deviation of the canopy element's spatial distribution from the random case; $L_{\mathrm{t}}$ is the plant area index $(\mathrm{PAI})$, which includes the LAI $(L)$ and the woody area index $\left(L_{\mathrm{W}}\right)$ such as the LAI is found with:

$L=\gamma_{\mathrm{E}}\left(L_{\mathrm{t}}-L_{\mathrm{W}}\right)=L_{\mathrm{t}} \gamma_{\mathrm{E}}(1-\alpha)$,

where $\gamma_{\mathrm{E}}$ quantifies the clumping of needles in shoots, referred as the needle-to-shoot area ratio, and can be measured from sampling of shoots in stands (Fassnacht et al., 1994; Stenberg et al., 1995; Chen et al., 1997). For broadleaf species, $\gamma_{\mathrm{E}}=1$. In deciduous species, the pre- or post-leaf emergence can be used to separate the woody to the total plant area (Chen, 1996a; Leblanc and Chen, 2001). $\alpha$ is the woody to total area ratio. Values of $\gamma_{\mathrm{E}}$ and $\alpha$ have been tabulated for several species and plots in the Canadian boreal forest (Chen et al., 1997; Gower et al., 1997).

The product of the clumping index with one of the area indices is referred as an effective measure (Chen, 1996a). The effective PAI, which is the product of the clumping index and the PAI, is the PAI inverted from gap fraction measurements with the assumption of randomly distributed canopy elements.

The importance of the clumping index in carbon models, in which the foliage is separated into sunlit and shaded leaves, has been demonstrated by Chen et al. (2003). To date, $\Omega(\theta)$ has usually been measured at one, or very few, zenith angles for a given stand. Chen (1996a) made clumping index measurements using gap size distributions (Chen and Cihlar, 1995a) with TRAC in boreal stands at several zenith angles. A clumping factor, reciprocal of the clumping index used here, was measured with hemispherical photographs by Van Gardingen et al. (1999) using Lang and Xiang finite-length averaging method for each annulus ring, but no angular separation was presented. Kucharik et al. (1997, 1999) used a two-band (visible and near-infrared) digital camera to measure gap fraction and gap size distribution to compute the zenith clumping index by comparing allometric LAI 
and gap fraction inverted LAI and with the gap size distribution method of Chen and Cihlar (1995a). Walter et al. (2003) use different methods to extract clumping index angularly from film-based hemispherical photographs, including a simplified version of Chen and Cihlar's theory. Although simplified, their results are generally similar to the results from Chen and Cihlar (1995a) method used here. Moreover, simulations of clumping index as a function of view zenith angles done with the five-scale model (Leblanc and Chen, 2000; Leblanc et al., 2002) show a wide range of curve shapes depending on input canopy architecture parameters.

Although many instruments already exist to quantify the LAI, they are usually expensive. Hemispherical photographs have been widely used to measure canopy structure (e.g. Rich, 1990; Chen et al., 1991; Fournier et al., 1996; Frazer et al., 2000), and to predict daily and seasonal understory photosynthetic photon flux density (PPFD) (e.g. Canham, 1988; Rich, 1990; Clearwater and Gould, 1995; Mizunaga, 2000). The recent advancement in digital cameras may have brought us a needed tool at a reasonable cost to estimate quantities such as the plant area and clumping index. Digital photographs made with a fish-eye lens allow the acquisition of hemispherical photographs without the need of scanners to digitize images and can be quickly inspected on the camera's viewer, or on laptop screen and in a timely fashion in the field. Moreover, for a given camera, the hemispherical images are of consistent size and position on the digital array. This retrieval can be done in a consistent manner at many zenith angles.

The goal of the present study is to describe in details the methodology used to measure canopy architecture using digital hemispherical photography
(DHP) and to compare different method of measuring foliage clumping. Results from DHP are compared with that of the commercial TRAC instruments.

\section{Materials and methods}

\subsection{Site description}

A wide range of forest stands were investigated as part of different field campaigns during the summers of 2000, 2001 and 2002. Table 1 contains specific information about the plots. Two deciduous plots were visited in Larose Forest, near Ottawa, Ontario, in June 2001. These two deciduous plots are the same plots described by Leblanc and Chen (2001). Several plots, approximately $150 \mathrm{~km}$ northwest of the Siberian city of Krasnoyarsk, Russia, were visited in 2000 and 2001. These plots are part of NASA SibLAI project (http://ltpwww.gsfc.nasa.gov/bsb/lai/ SibLAI.html). A subset of the SibLAI plots is used in this study where both TRAC and digital hemispherical photographs were acquired. Two mixed aspen and spruce plots near Smooth Rock Falls, in Northern Ontario, that have been severely plagued by the tent caterpillar for many years, in which the mortality level is high, were visited on June 19, 2001. These two plots are part of the Ontario side of the Climate Change Impacts on the Productivity and Health of Aspen (CIPHA) project (Keiser et al., 2002). Many plots near Thompson, Manitoba, were visited from July 10 to 22, 2002. These plots are in the same region as the BOREAS Northern Study Area (Sellers et al., 1997), and two plots (namely, T04 and T13) are part of the FIRe Ecosystem and Succession-Experiment Boreal (FIRES-ExB) (Bond-Lamberty et al., 2002).

Table 1

Site descriptions

\begin{tabular}{|c|c|c|c|c|}
\hline Site & Location & Year & Species & Camera \\
\hline Larose & $45^{\circ} 23^{\prime} \mathrm{N}, 75^{\circ} 11^{\prime} \mathrm{W}$ & 2000,2001 & $\begin{array}{l}\text { Populous tremuloides Michx, } \\
\text { Betula papyrifera, Accer Sacharum }\end{array}$ & CoolPix 990/5000 \\
\hline Krasnoyarsk & $56^{\circ} 57^{\prime} \mathrm{N}, 91^{\circ} 33^{\prime} \mathrm{E}$ & 2000,2001 & $\begin{array}{l}\text { Populus tremula, Betula pendula, } \\
\text { Picea obovata, Abies siberica, Pinus siberica }\end{array}$ & CoolPix 990 \\
\hline Smooth Rock Falls & $49^{\circ} 15^{\prime} \mathrm{N}, 82^{\circ} 3^{\prime} \mathrm{W}$ & 2001 & Picea glauca, Abies balsamea & CoolPix 990 \\
\hline Thompson & $55^{\circ} 53^{\prime} \mathrm{N}, 98^{\circ} 29^{\prime} \mathrm{W}$ & 2002 & Picea mariana, Pinus banksiana & CoolPix 5000 \\
\hline
\end{tabular}




\subsection{Gap fraction inversion}

Gap fraction inversions have often been used to estimate the foliage density of canopies based on different models. Simple models, such as BeerLambert's law (Eq. (1)), are commonly used while more complex models that consider explicitly crowns placement (e.g. Fournier et al., 1996; Nilson, 1999) are less popular as they often require measurements such as stems density, crown size, DBH, and estimation of foliage crown density. Complex inversions are best suited for stands where stem density and crown size are known or uniform crown conditions are found. Inversion of Beer-Lambert's, using Miller's theorem (1967) and adding clumping index angular variation gives (Fernandes et al., 2001):

$L_{\mathrm{t}}=-2 \int_{0}^{\pi / 2} \frac{\ln [P(\theta)]}{\Omega(\theta)} \cos \theta \sin \theta \mathrm{d} \theta$.

Eq. (3) demonstrates that to get an accurate estimate of the plant area index, zenithal measurements of both gap fraction and clumping index are needed. It is implied in Eq. (3) that the gap fraction $P(\theta)$ is the mean gap fraction measured at that angle. However, Chen et al. (1997) used a single plot-specific clumping index retrieved by TRAC at solar zenith angles ranging from 30 to $60^{\circ}$ to correct LAI-2000 (LI-COR Incorporated Lincoln, Nebraska, USA; LI-COR, 1991) measurements with the assumption that the angular dependency was negligible compared to the variability between stands; their optically based LAI compared well with allometric LAI up to 6 in boreal forests. Inversion of Eq. (1) can be done using Eq. (3) or at $\theta$ equals $57.3^{\circ}$ where $G(\theta)$ is always near 0.5 (Neumann et al., 1989; Leblanc and Chen, 2001; Leblanc et al., 2002). In both inversion methods, the only two required parameters to get PAI are the gap fraction and clumping index.

\subsection{Clumping index}

The clumping index can be estimated at any zenith angle using measurements of gap fraction, foliage orientation and LAI from destructive sampling or allometric equations (Kucharik et al., 1997; Nilson, 1999). However, this is a time consuming method, and the foliage orientation is usually assumed random to simplify the process. Different approaches have been used to measure the clumping index using only optical instruments and without the need of the foliage orientation.

\subsubsection{Clumping index from gap size distribution}

For a canopy with random foliage distribution at any zenith angle $\theta$, the fraction of gap larger than the length $\lambda$ can be written as (Chen and Cihlar, 1995a):

$F(\lambda, \theta)=\left[1+L_{\mathrm{p}}(\theta) \frac{\lambda}{W_{\mathrm{p}}(\theta)}\right] \mathrm{e}^{-L_{\mathrm{p}}(\theta)\left[1+\lambda / W_{\mathrm{p}}(\theta)\right]}$

where $F(\lambda, \theta)$ is the accumulated gap fraction, $W_{\mathrm{p}}(\theta)$ the foliage element mean projection width along the $\theta$ direction and $L_{\mathrm{p}}(\theta)$ the projected leaf area index. The clumping index at any zenith angle can be found with, after a modification by Leblanc (2002):

$\Omega_{\mathrm{CC}}(\theta)=\frac{\ln \left[F_{\mathrm{m}}(0, \theta)\right]}{\ln \left[F_{\mathrm{mr}}(0, \theta)\right]} \frac{\left[1-F_{\mathrm{mr}}(0, \theta)\right]}{\left[1-F_{\mathrm{m}}(0, \theta)\right]}$

where $F_{\mathrm{m}}(0, \theta)$ is the measured accumulated gap fraction larger than zero, i.e. the canopy gap fraction, and $F_{\mathrm{mr}}(0, \theta)$ is the gap fraction for the canopy when large gaps that are not theoretically possible in a random canopy have been removed for a given $L_{\mathrm{p}}(\theta)$ and $W_{\mathrm{p}}(\theta) . L_{\mathrm{p}}(\theta)$ is estimated based on the gap fraction at $\theta$. Estimating $W_{\mathrm{p}}(\theta)$ is not straightforward when this method is applied to hemispherical devices, since a pixel, which represents a given solid angle, is not a direct indicator of the foliage physical length (shadow) as used in the TRAC measurements taken perpendicular to the sun. The resolution of hemispherical images, the foliage distance to the lens and the canopy height can all change the typical element width $W_{\mathrm{p}}(\theta)$. To get an estimate of $W_{\mathrm{p}}(\theta)$, another methods, from Chen and Black (1992b), can be used. The method was developed to retrieve $W_{\mathrm{p}}(\theta)$ from another description of a canopy with randomly distributed foliage (based on Miller and Norman, 1971):

$P_{\mathrm{m}}(\lambda, \theta)=\mathrm{e}^{-L_{\mathrm{p}}(\theta)\left[1+\lambda / W_{\mathrm{p}}(\theta)\right]}$

where $P_{\mathrm{m}}(\lambda, \theta)$ is the probability that a probe of length $\lambda$ falls completely within a sunfleck on the forest floor, while $L_{\mathrm{p}}(\theta)$ and $W_{\mathrm{p}}(\theta)$ are the same quantities as in Eq. (4). Eq. (6) can be used to estimate the typical width element $W_{\mathrm{p}}(\theta)$ from the measurements:

$W_{\mathrm{p}}(\theta)=-\frac{\ln \left[P_{\mathrm{m}}(0, \theta)\right]}{\left|\partial \ln \left[P_{\mathrm{m}}(\lambda, \theta)\right] / \partial \lambda\right|_{\lambda=0}}$. 
See Chen and Cihlar (1995b) for a comparison between applications of Eqs. (4) and (6). Since measured gap size distributions in canopies do not necessarily have a random foliage distribution, $W_{\mathrm{p}}(\theta)$ cannot be retrieved directly from the measured gap size distribution. It needs to be retrieved from a "compacted" random canopy found after the gap removal used to retrieve the clumping index. However, the gap removal requires a value of $W_{\mathrm{p}}(\theta)$ to calculate the theoretical $F(\lambda, \theta)$ to be compared with the measured $F_{\mathrm{m}}(\lambda, \theta)$. Although this gives a reduced $F_{\mathrm{mr}}(\lambda, \theta)$, one needs to redo the reduction process as the $W_{\mathrm{p}}(\theta)$ representative of the canopy foliage is needed from step one. This one iteration is sufficient for $W_{\mathrm{p}}(\theta)$ to converge since the gap size at which the reduction stops is not very sensitive to a change in $W_{\mathrm{p}}(\theta)$ once the large gaps that are clearly not possible for a given gap fraction are removed. The clumping index from Chen and Cihlar (1995a,b) method is referred hereinafter as CC.

\subsubsection{Clumping index from logarithmic average}

Lang and Xiang (1986) were the first to present a methodology to use logarithmic averages for LAI estimation with a solid statistical background. They stated that the leaf area index in a discontinuous (clumped) canopy could be found more accurately by averaging the canopy transmittance in a logarithmic fashion (hereinafter referred to as method LX). The average gap fraction is to be calculated within a finite length equal to 10 times the mean width of a foliage element. The LX method assumes

(1) the foliage within the finite length is random, and

(2) the segment contains gaps.

The reasoning behind this technique is that since the LAI is related to the natural logarithm of the gap fraction (from Eq. (1)), the average LAI should follow the logarithm average of the gap fraction. For the LX method, the clumping index is calculated as:

$\Omega_{\mathrm{LX}}(\theta)=\frac{\ln [P(\theta)]}{\overline{\ln [P(\theta)]}}$

where $P(\theta)$ is the canopy mean gap fraction and $\overline{\ln [P(\theta)]}$ the logarithmic mean gap fractions of all segments. A segment with no gap, or very small gap fraction, affects clumping index and LAI retrieval as the logarithm of a near zero, or zero, gap fraction value gives an infinitely high LAI. The finite-length method has been known to give erroneous results, as gaps may not exist over the short length of the suggested ten-leaf width segments in a clumped canopy (Chen and Black, 1992b; Whitford et al., 1995). However, other studies have been more successful in using the LX method (Baret et al., 1993; Sommer and Lang, 1994; Fassnacht et al., 1994; Brenner et al., 1995; Van Gardingen et al., 1999).

The assumption of random foliage may not be true if the logarithm average is calculated for length longer than 10 times the leaf width since large gaps between crowns give erroneous results, or over very short segments since the Poisson theory used to derive Eq. (1) assumes an infinite canopy to achieve the exponential relationship. It is very difficult to meet both segment size assumptions, so this method needs to be used carefully. To solve the logarithmic problem, segments with no gaps have been artificially altered by adding a gap of one pixel by Van Gardingen et al. (1999). There are no priori reasons why this should work since the one pixel gap added is dependent on the pixel resolution of the photograph. Another solution was used by Walter et al. (2003) where the segments with no gap were removed from the calculations. We selected our segments to be larger than the segment size for which Van Gardingen et al. (1999) found an asymptotic behaviour of their clumping factor to avoid segments with no gaps.

\subsubsection{Clumping index using both gap size and logarithm methods}

Considering the two problems of segment length associated with the LX method, a new method is tested here to compensate when large segments are not homogeneous. To address this within segment foliage heterogeneity, the $\mathrm{CC}$ method is used within the segments. Only large gaps within the segment will affect the clumping calculated with this new method (hereinafter referred to as CLX). The overall clumping index is then calculated over $n$ segments as:

$\Omega_{\mathrm{CLX}}(\theta)=\frac{n \ln [\overline{P(\theta)}]}{\sum_{k=1}^{n} \ln \left[P_{k}(\theta)\right] / \Omega_{\mathrm{CC} k}(\theta)}$ 
where $\Omega_{\mathrm{CC} k}(\theta)$ is the element clumping index of segment $k$ using the $\mathrm{CC}$ method and $P_{k}(\theta)$ is the gap fraction of segment $k$.

\subsection{Foliage projection coefficient}

With the knowledge of the clumping index, the foliage projection coefficient can now be more accurately estimated from inverting Eq. (1) as:

$G(\theta)=-\frac{\ln [P(\theta)] \cos \theta}{L_{\mathrm{t}} \Omega(\theta)}$.

Although different methods exist to estimate the foliage angular distribution from $G(\theta)$, we limit the retrieval to $G(\theta)$ itself as the general information needed in models is found in its angular behaviour.

\subsection{Tracing radiation and architecture of canopies (TRAC)}

TRAC is a commercially available optical instrument (3rd Wave Engineering, Ottawa) that measures photosynthetic photon flux density (PPFD) at a frequency of $32 \mathrm{~Hz}$ (Chen and Cihlar, 1995a; Chen, 1996a). By walking the instrument under a canopy, the gap fraction and gap size distribution can be estimated from sunfleck measurements. The gap fraction is used to estimate the effective PAI, while the gap size distribution is used to estimate the clumping index (method CC). The TRAC data analysis is done with a proprietary program, TRACWin (Leblanc et al., 2002). Input parameters include segment length, typical foliage element size $W_{\mathrm{p}}(\theta)$, and coordinates of the plot and acquisition time to compute the solar zenith angle. The iteration method to estimate $W_{\mathrm{p}}(\theta)$ from the measurements developed for hemispherical photography can also be used with TRAC data. On terrains with important topography effects, the slope and aspect are needed to calculate the solar beam incident angle. However, all plots used in this study are on terrains with negligible slopes.

\subsection{Digital hemispherical photography}

In recent years, off-the-shelf digital cameras have finally reached a quality standard that can start competing with film-based camera. Digital cameras acquire photographs using a couple charge device
(CCD) matrix. A CCD is a light-sensitive integrated circuit that is placed at the focal plane of an optical imaging system and is assumed to have a linear response to light. The cameras' resolution, usually quantified in mega pixel, can now allow an angular resolutions better than $0.5^{\circ}$, which is the sun angular disc solid angle. Fig. 1a shows the theoretical azimuth and zenith angular resolution of a photograph taken with a fish-eye lens mounted on a digital camera with a 1500-pixel circular projection diameter. From view zenith angles of $15^{\circ}$ and larger, the resolution is better than $0.5^{\circ}$. The zenithal and azimuthal resolutions are identical only at $57.3^{\circ}$ (unit radians), which is also the angle at which the LAI extraction is equivalent to Miller's theorem. When the resolution is transformed into gap size at the top of the canopy, assuming a
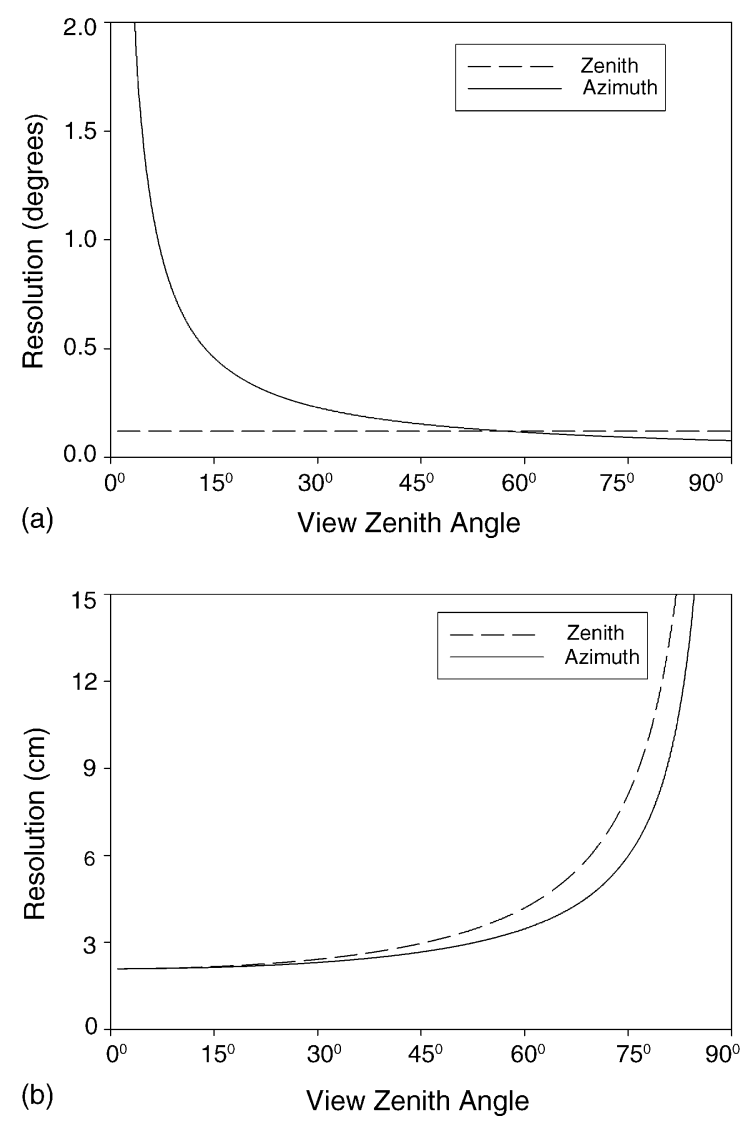

Fig. 1. (a) Azimuth and zenith resolutions of a 1500-pixel (in diameter) hemispherical image, and (b) pixel resolutions at the top of a $10 \mathrm{~m}$ canopy for the same image. Note that the two curves in (a) crosses at $57.3^{\circ}$. 
canopy that extends $10 \mathrm{~m}$ higher than the camera, the minimum gap size that a pixel represents increases as the view zenith angle increases (see Fig. 1b), but it is generally under $6 \mathrm{~cm}$ up to a view zenith angle of $70^{\circ}$.

The characterization of canopy structure from filmbased versus digital hemispherical photographs has been assessed with different degrees of success (Englund et al., 2000; Frazer et al., 2001; Hale and Edwards, 2002). These comparisons show a large scatter in agreement between both sensors that may be, in large part, due to the comparison at the photograph level. Chen et al. (1997) compared LAI-2000 and film hemispherical photographs for LAI retrieval and their plot level retrievals gave much better agreement than the single point level. Errors in the placement and levelling of the camera tend to average out over many photographs in a plot and hence isolate the sensor dependent differences. The minimum number of photographs used for a given plot is six in this study.

The digital cameras used in this study are the Nikon CoolPix 990 and 5000. The choice came from availability of fish-eye lens for this camera type, full circular projection on the CCD array and the affordable cost. The highest resolution setting of the CoolPix 990 and 5000 produces images of $2048 \times 1536$ and $2560 \times 1920$ pixels, respectively. The fish-eye lens adaptor used is the FC-E8 adapter, which has a field of view of $183^{\circ}$. Frazer et al. (2001) reported a distortion in the FC-E8 lens and suggested a third order polynomial correction equation. We adapted their distortion equation to angular properties independent of image size:

$\theta_{\mathrm{c}}=4 E-06 \theta^{3}+0.0003 \theta^{2}+0.9375 \theta$

where $\theta_{\mathrm{c}}$ is the corrected zenith angle (in degrees) and $\theta$ is the zenith angle assumed from linear $\theta$-pixel properties. We applied this correction factors to all our data. The diameter of the $180^{\circ}$ circular-projected hemispherical photographs was estimated as 1350 and 1375 for the CoolPix 990 and 5000, respectively.

All digital phtographs were either saved in high quality JPEG or TIFF formats. Frazer et al. (2001) compared LAI retrieved from TIFF and JPEG digital hemispherical photographs and concluded that the difference was small as long as the file size compression ratio used in the JPEG is at least 1/4.

Some other artifacts may be found in photographs such as chromatic aberration that is due to light bending differently in different wavelengths due to imperfection of the lens systems. This problem is more important when using the three image planes. By using only a single channel, the effect is greatly diminished as chromatic aberration changes the focus of an image planes relative to the other two. The technology is also improving fast and newer CoolPix (e.g. models 4500 and 5700; Digital Photography Review, 2003) have less chromatic aberration than the models used in this study. It must be noted that the CoolPix 990 and 5000, along with many off-the-shelf digital cameras currently available, do not have separate sensors for the RGB (red-green-blue) channels. This means that the blue channel used in this study may not be completely independent to the other two channels. Some of the new and more expensive digital cameras have the complete separation of the three visible channels. Blooming, which is due to saturation of a CCD element that spills over to neighbouring elements on the array, is an important problem when using hemispherical photographs for quantitative measurements. It is usually more important near the zenith and under sunlit conditions or overcast days when the grey sky is very bright. However, digital hemispherical photographs taken during daytime on overcast day tend to have slightly more blooming in the blue compare to the other two bands.

\subsection{Digital Hemispherical photographs acquisition}

Several methods have been presented to get the perfect exposure using film camera. Digital cameras offer an instant viewing modes that can simplify the acquisition. We used the following protocol for acquiring the photographs.

The camera is used in the manual mode with the light indicator at zero, or minus one or two. Once a photo is taken, the play mode of the camera is used to assess the photograph's quality and contrast. Dark foliage is required with few saturated pixels. The areas with saturation can be seen on the display, and the goal is to have some saturation, but only when the saturated areas are without foliage. This usually gave a wide dynamic range of DNs with low blooming effects.

\subsection{Digital hemispherical photographs processing}

Most of the problems due to image acquisition and analysis of hemispherical photographs reported by 
Rich (1990) still apply to digital hemispherical photographs. However, some of the problems associated with image digitization have been solved with digital cameras. This section improves on previous techniques developed for film-based hemispherical photographs analysis. Techniques proposed by Wagner $(1998,2001)$ for film camera are also adapted and applied to digital photographs.

\subsubsection{Gap fraction}

An in-house research program, named "DHP.exe", that runs on Microsoft Windows ${ }^{\mathrm{TM}}$ environments (95 and later), was developed to read uncompressed 8-bit "raw" images (Leblanc, 2004). Both TIFF and JPEG images are composed of three 8-bit image planes (red, green and blue) with 256 intensity levels $(0-255)$ per channel. The intensity level is often referred to as digital number (DN). Available software uses either one or the three image channels for the analysis (e.g. GLA, Frazer et al., 1999), but they cannot be used to try new analysis methods. An assessment of photographs taken under different sky illumination condition was done and the blue channel was preferred as the basis for the image analysis because the foliage elements have a much lower reflectivity and transmittance in the blue region of the visible electromagnetic spectrum, making the foliage darker than in the red or green bands. This is why the LAI-2000 plant canopy analyzer uses only visible radiation below $490 \mathrm{~nm}$ for monitoring forest structure (LI-COR, 1991). Fig. 2 shows how important this optical property of the foliage compares to blooming. Blooming is mainly found in large openings and at high sky radiance near the zenith. Fig. 2a shows that (a)

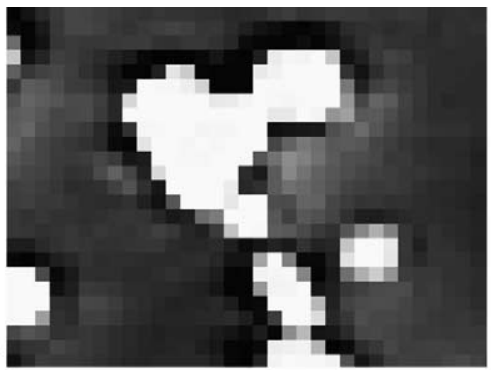

(b)

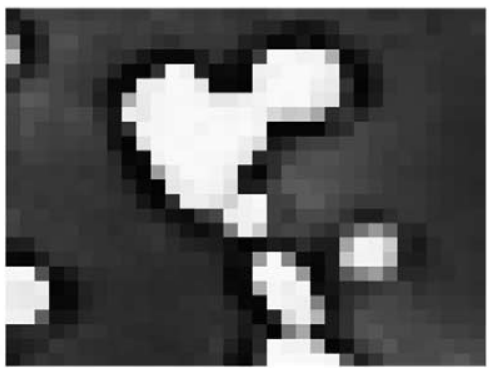

(c)

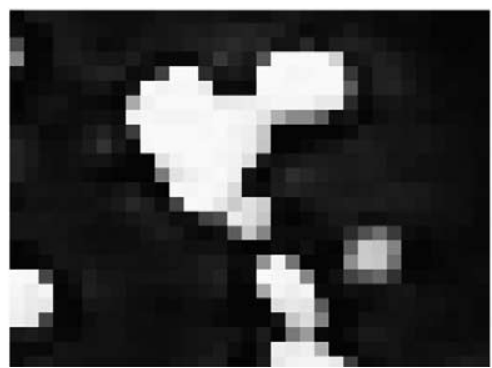

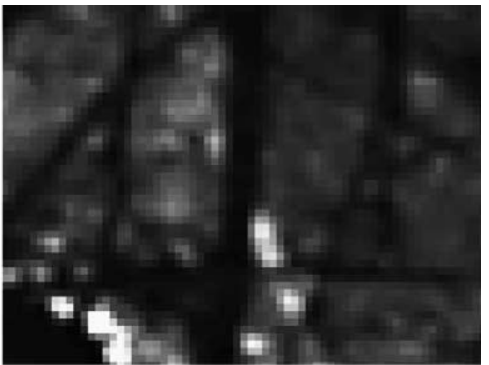
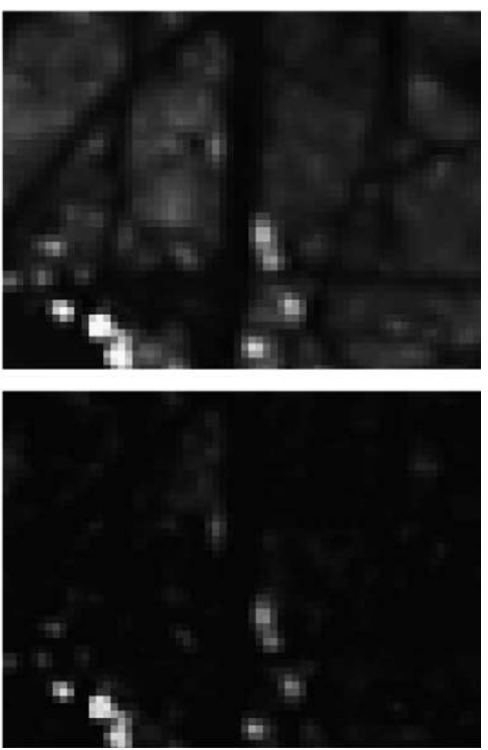

Fig. 2. Magnification of the three channels of hemispherical photographs without any digital enhancement, from low view zenith angle on the left-hand-side and at high view zenith angle on the right-hand-side: (a) the red, (b) the green and (c) the blue band channels. 
blooming affects all three channels and that a few pixels that have very high DN values (high grey intensity) in the red and green have disappeared in the blue image. However, at higher zenith angles (Fig. 2, right-hand side), such effect is not generally seen, while the red and green channels still have very bright foliage elements. The histograms of the hemispherical photograph from the same deciduous stand of Fig. 2 taken under sunlit conditions from a $9^{\circ}$ annulus ring centred at $49^{\circ}$ in Fig. 3a shows that the information in the red and green bands are similar while the blue band
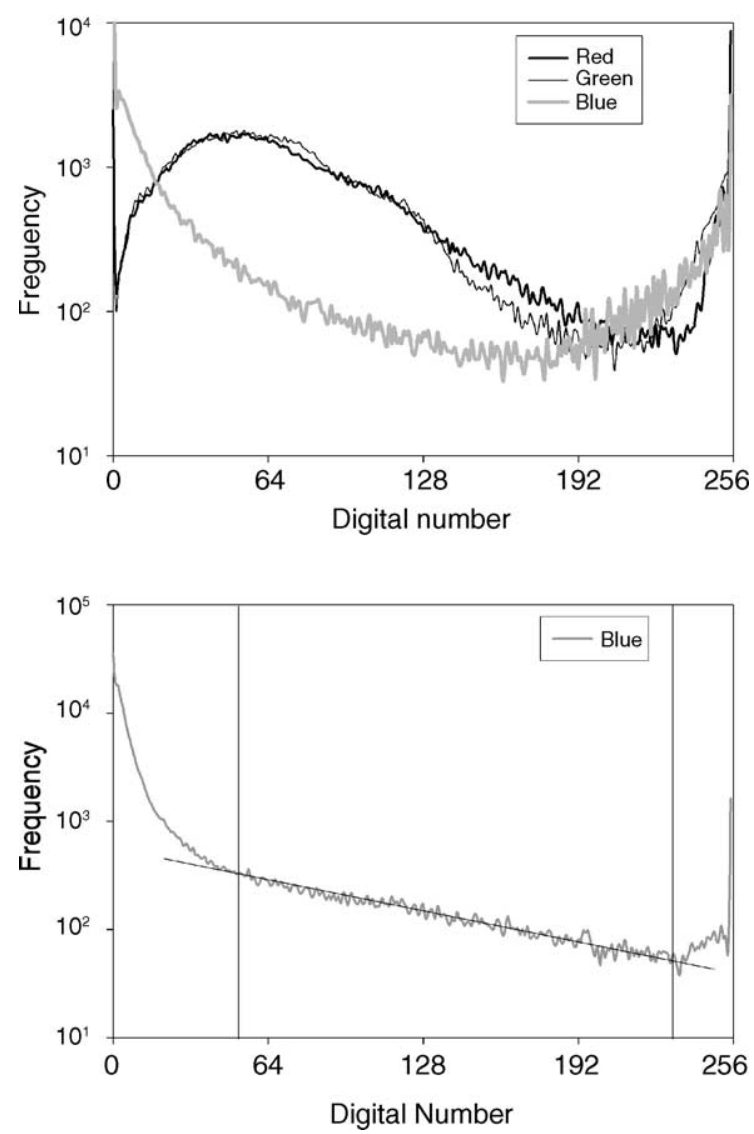

Fig. 3. Digital number histogram of a $9^{\circ}$ annulus of a single digital hemispherical photograph (a) centred at view zenith angle $49^{\circ}$ from stand D1 of Larose Forest taken on July 7, 2002 for the three image channels (red, green and blue) and (b) only the blue channel centred at $58^{\circ}$ the 72 black spruce plot (T04) near Thompson, Manitoba. The $y$-axis is in a logarithm scale to put emphasis on the mixed pixel part of the histogram (in b) found between the two thresholds (DNs 50 and 220). The thresholds are set where the histogram digital number values start to deviate from the straight line in the logarithmic plot. is different. Even with the three CCD channels not being completely independent, the blue channel still shows a very different profile. The increased blooming in the blue band is only important near the zenith, while the increased reflectivity and transmittance problem for the red and green channels is present at all angles. This will be assessed with two cases, one under diffused and one under sunlit conditions.

Several steps are needed in the DHP's analysis. First, the image blue channel is extracted and saved in a raw 8-bit format. For the photographs taken under sunlit conditions, the very bright trunks were hand painted in black (with $\mathrm{DN}=0$ ). This removes a large part of the effect of light scattering on subsequent analysis, as the trunks may appear as bright as the sky in the blue band. Any sky pixel with insects on them was replaced with the maximum DN value of 255 . The image is then analysed with DHP.exe in a fixed number of zenithal annulus segments. We used a 10 rings configuration for the thresholding, but the results can be made at other numbers of annulus rings. Tests with the six rings case equivalent to the LAI-2000 gave very similar results.

The second step involves the thresholding of the DHP blue channel image to separate sky from canopy pixels. This is a basic two-population image classification problem. A single threshold is generally used for the whole image for both digital and film-based hemispherical photographs (e.g. Frazer et al., 2001), although Wagner (1998) and Olsson et al. (1982) have used two-threshold methods with film-based photography. In this study, two threshold values for each annulus are used. The analysis is done for each annulus separately to minimize the difference in multiple scattering in the canopy, the difference in sky radiance, and any vignetting effect of the lens (Wagner, 2001). The two thresholds are used to separate the pixels into three categories: sky, canopy, mixed sky canopy. Fig. 3b gives a visual example of the thresholds found. The low threshold separates complete foliage filled pixels from mixed sky and foliage pixels. The high threshold separates the foliage free (gap) pixels from mixed foliage and sky pixels. For the mixed pixels, the linearity of the camera CCD array is used to calculate the within pixel gap fraction. Photographic film does not have a linear response to light, so the sub-pixel gap fraction is not as easily found from film-based hemispherical photographs 
(see Wagner, 1998). Assuming a linear CCD array and very low scattering of light by the canopy, the gap fraction within a pixel is estimated as: find the thresholds, but the values are only used as the first estimate and are always overwritten by the user. The program finds the thresholds with simple

$$
\begin{array}{ll}
P(\theta)=0, & \text { for } \mathrm{DN}(\theta)<\mathrm{DN}_{\text {Min }}(\theta) ; \\
P(\theta)=\frac{\mathrm{DN}(\theta)-\mathrm{DN}_{\mathrm{Min}}(\theta)}{\mathrm{DN}_{\mathrm{Max}}(\theta)-\mathrm{DN}_{\mathrm{Min}}(\theta)}, & \text { for } \mathrm{DN}_{\text {Min }}(\theta)<\mathrm{DN}(\theta)<\mathrm{DN}_{\mathrm{Max}}(\theta) ; \\
P(\theta)=1, & \text { for } \mathrm{DN}(\theta)>\mathrm{DN}_{\operatorname{Max}}(\theta) .
\end{array}
$$

The thresholds $\operatorname{DN}_{\text {Min }}(\theta)$ and $\operatorname{DN}_{\text {Max }}(\theta)$ can be found either visually by inspecting the image and numerically from the histogram. Eight-bit images give a range of 256 light intensity levels and the two thresholds used to separate sky from canopy pixels induce a maximum radiometric range of about 100 DNs. This means that the gap size resolution is at best $1 / 100$ of the pixel size. Future cameras may be able to save the blue channel at higher digital resolution than the current 8-bit level. This increased level of subpixel gap size resolution may improve results within very dense canopies. Photographs taken under sunlit conditions tend to have a smaller radiometric range of about 10-20 DNs. The DHP.exe software has a simple visualization window and a histogram view that are used to assist the threshold estimation. All DNs that are pure gaps are colour coded in white and all pure canopy pixels are in black. The mixed-pixels are coded in shades of green. The display can be switched between the original 256 shades of grey and the colour coded modes to facilitate the thresholding. Moreover, each annulus can be displayed separately, along with its histogram. Generally, when blooming is negligible, $\operatorname{DN}_{\text {Min }}(\theta)$ is found where the linear part of the histogram in a logarithm scale starts while $\operatorname{DN}_{\text {Max }}(\theta)$ is found where the linear part ends (see Fig. 3b). When no linear behaviour can be found on the histogram (e.g. Fig. 3a), only the visual inspection of the image colour coded with the thresholds compare to the original 8-bit blue channel can be used to find the correct thresholds, or adjacent ring thresholds can be used. All thresholds were found by the same person through manual inspection of the image and the histogram in this study. Tables 2 and 3 show thresholds found manually for black spruce (T04 and T01) and mixed deciduous (D1) stands. The thresholds generally decrease with increasing view zenith angle. The current software has a simple automated method to maximum occurrence of DN from the histogram. The low threshold is found from the histogram most occurring DN that is less than 75 , to which 30 grey levels is added, while the high threshold is from the most occurring DN larger than 75 minus 15 levels. The thresholds are checked and changed with the average of all annuli for any annulus in which the threshold is not within 2.5 standard deviations (see Table 2). Automated thresholding using sky irradiance formu-

Table 2

\begin{tabular}{|c|c|c|c|c|}
\hline \multirow[t]{2}{*}{ View zenith angle $\left(^{\circ}\right)$} & \multicolumn{2}{|l|}{ T01 } & \multicolumn{2}{|l|}{ D1 } \\
\hline & $D_{\text {Min }}$ & $D_{\text {Max }}$ & $D_{\text {Min }}$ & $D_{\text {Max }}$ \\
\hline 4 & 115 & 195 & 68 & 156 \\
\hline 13 & 115 & 188 & 51 & 197 \\
\hline 22 & 110 & 186 & 60 & 198 \\
\hline 31 & 111 & 178 & 53 & 196 \\
\hline 40 & 108 & 176 & 51 & 195 \\
\hline 49 & 101 & 173 & 50 & 186 \\
\hline 58 & 80 & 163 & 52 & 198 \\
\hline 67 & 67 & 159 & 47 & 187 \\
\hline 76 & 65 & 133 & 54 & 192 \\
\hline 85 & 65 & 122 & 51 & 176 \\
\hline
\end{tabular}

Automated and manual thresholds for plot T04

\begin{tabular}{llllll}
\hline View zenith angle $\left(^{\circ}\right)$ & \multicolumn{2}{l}{ Automated } & & \multicolumn{2}{c}{ Manual } \\
\cline { 2 - 3 } \cline { 6 - 6 } \cline { 5 - 6 } & $D_{\text {Min }}$ & $D_{\text {Max }}$ & & $D_{\text {Min }}$ & $D_{\text {Max }}$ \\
\hline 4 & 64 & 233 & & 108 & 205 \\
13 & 64 & 233 & 96 & 209 \\
22 & 57 & 233 & 91 & 222 \\
31 & 47 & 233 & 93 & 216 \\
40 & 42 & 233 & & 103 & 219 \\
49 & 42 & 228 & 99 & 224 \\
58 & 41 & 235 & 92 & 224 \\
67 & 41 & 235 & 90 & 220 \\
76 & 41 & 235 & 66 & 226 \\
85 & 41 & 186 & 23 & 206 \\
\hline
\end{tabular}

Table 3

Manual thresholds for plot T01 and D1 
lation and image vigneting (see Wagner, 2001) may be added in future version of the program. For a given stand with low foliage spatial variability, it is common to have the same, or very similar, thresholds for many photographs.

\subsubsection{Clumping index}

The specific clumping index retrieval technique used for the DHP is described in this section. The DHP.exe program extracts azimuthal DN profiles of 1 pixel, representing about $0.1^{\circ}$, in a zenith range in order to mimic a PPDF profile to estimate canopy gap size (see Fig. 4a and b). With the CoolPix 5000, a complete annulus has about 700 and 2700 pixels at view zenith angles of 10 and $57^{\circ}$, respectively. There are about $2 \%$ fewer pixels than those to cover the exact circumference at a given view zenith angle on the image due to quantization effect attributed to the angular resolution on the CCD digital array. Each extracted DN value is saved in a normalized format since the thresholds may vary substantially from image to image due to different illumination conditions and camera settings. The normalization is done using the thresholds found in each annulus rings with an optional linear interpolation between two thresholds to remove potential "jagged edge" effects. Based on Eq. (12), Pixels with DNs larger than the maximum threshold $\mathrm{DN}_{\text {Max }}(\theta)$ are given the value $1000(100 \%$ gap), pixels with DNs less than the lower threshold become 0 (0\% gap), and mixed pixels are found between 0 and 1000. A marker is inserted every $45^{\circ}$ in azimuth in the data stream, thus separating a $360^{\circ}$ annulus into eight segments. This choice is arbitrary and does not influence the results in any way when using the CC method, but it is needed to use the existing software TRACWin.exe developed for TRAC data analysis (Leblanc et al., 2002) as the number of data points in a segment is limited. The choice is important for the LX and CLX method and was chosen to be larger than the segment used by Van Gardingen et al. (1999). TRACWin.exe was developed at Canada Centre for Remote Sensing and is distributed freely with the TRAC instrument. However, since the software was developed for PPFD profiles taken by walking the TRAC on line transects under canopies, the required inputs are modified to represent the
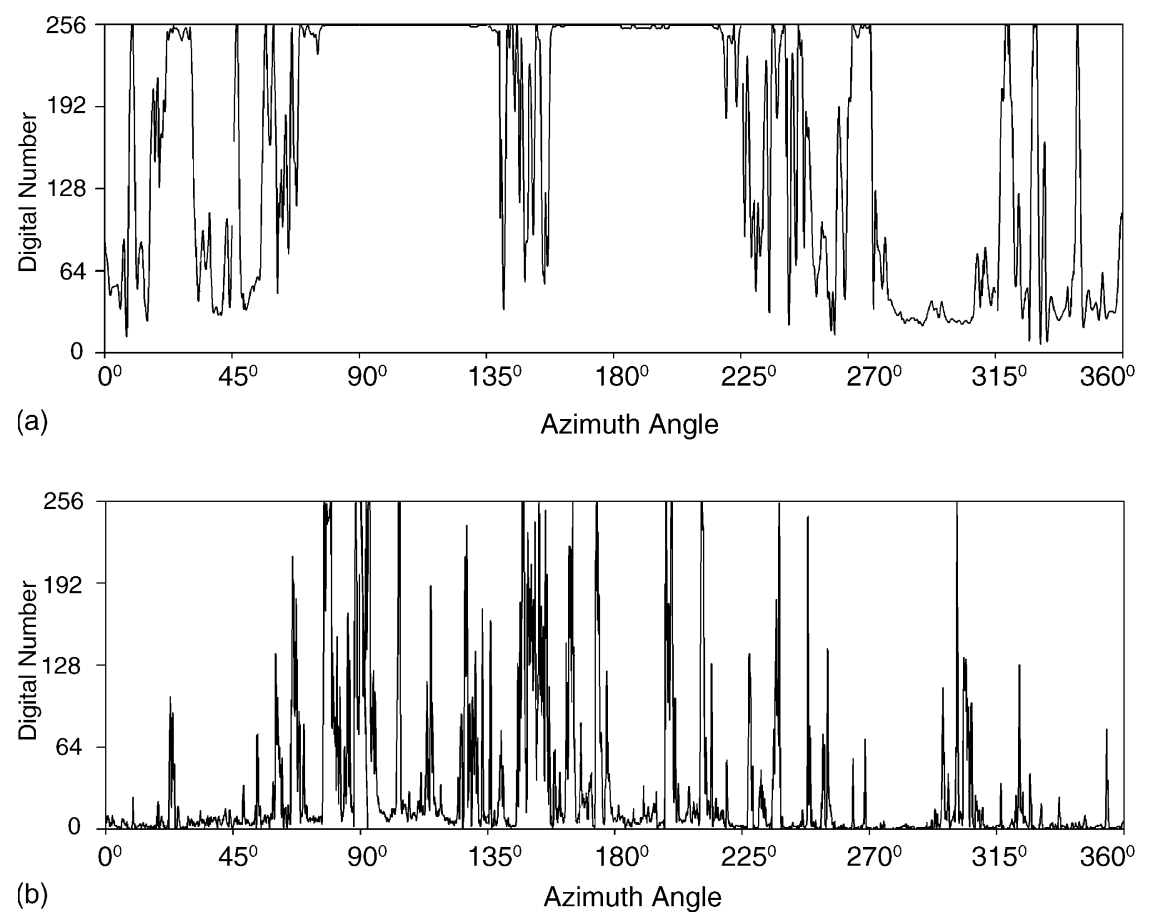

Fig. 4. TRAC-like DN profiles from one digital hemispherical photograph at plot T04 for (a) view zenith angle $10^{\circ}$ and (b) view zenith angle $57^{\circ}$. The profiles are in 1-pixel intervals in the zenith angle resolution. 
azimuth measurements of DHP. The space between markers (one segment), which is in meter for TRAC measurements, and is now $45^{\circ}$ in azimuth, is set to a value related to the number of pixels in the $45^{\circ}$ segment (e.g. number of pixels in the segment divided by 100) to bring the gap size values in the range of values that the software can handle. This is done automatically by TRACWin.exe (version 2.6 and more recent) when using outputs created by DHP.exe. The typical mean element $W_{\mathrm{p}}(\theta)$ is then expressed in percentage of the pixel resolution.

Each segment is analyzed and the gap size distribution for that segment is used to estimate its element clumping index $\left(\Omega_{\mathrm{CC} i}(\theta)\right)$. This automatically processes the data for the CC, LX and CLX methods. For the LX and CLX methods, the problem of segments without gaps is solved in a manner similar to that of Van Gardingen et al. (1999). Segments with no gaps were given the following maximum effective plant area index (PAIe) value:

PAIe $_{\text {Max }}(\theta)=-2 \ln \left(P\left[\frac{0.5}{N_{\text {pixel }}}\right]\right) \cos \theta$

where $N_{\text {pixel }}$ is the number of pixels in a segment. Half a pixel is used because with our methodology subpixel gaps are possible. Because of sub-pixel information that can be less than half a pixel, it is possible that a given segment will have a larger PAIe than the maximum calculated by Eq. (13). We forced all PAIe greater than PAIe $_{\text {Max }}$ to be equal to PAIe $_{\text {Max }}$. PAIe $_{\text {Max }}$ varies from around ten at the zenith and decrease to about two at view zenith angle of $80^{\circ}$.

\section{Results and discussion}

\subsection{DHP gap fraction}

Many aspects of the analysis can induce errors in the gap fraction estimation. The first error comes from the image thresholding. This error is dependent on the specific histogram for a given annulus and image channels. Tests in Krasnoyarsk site K2.2, using the best thresholds possible for each band with photographs that show apparent blooming, indicate that the gap fraction estimates at all angles are within a R.M.S. of 0.02 between the three channels. The blue channel has higher gap fraction (about 0.01) than the red and green near the zenith, but it has lower gap fraction than the red and green channels at higher zenith angle (about 0.02). Therefore, the safest choice is to use the blue band as the weight in calculating LAI is at higher view zenith angles, but the other two bands seems to generally give similar results. Tests were also performed to assess the improvement of using angular thresholds. The need for this new thresholding method is clear when a single image is viewed with the same threshold (or double thresholds) for a whole image. Some sky pixels appear as canopy pixels when the sky brightness is close to foliage brightness at the top of the canopy. The effect of using thresholds that have angular dependence is about $1-3 \%$ in terms of gap fraction, but it can result in 5-10\% changes for the resulting LAI depending on the threshold values chosen and gap fraction of the canopy.

All hemispherical photographs from plot Larose D1 were analysed using the sub-pixel gap method described above, and with the lower thresholds set to be the same as the higher thresholds. This has the equivalent effect of removing all gaps smaller than one pixel. This is not exactly the same as the usual onethreshold method for two reasons: first, each annulus still has its own threshold while the usual method only has a single threshold for a given image; and second, the single threshold usually found is not necessary the highest of our two thresholds, it is a value between the low and high thresholds. Setting the two thresholds to the maximum is then a worst-case scenario. Fig. 5a shows that the effect is sizeable, but still within reasonable ranges. A more realistic test was performed by comparing the gap fraction estimated from the thresholds found automatically by DHP.exe with the thresholds found by the operator for plot T04. This is not to assess the automated retrieval of the thresholds since the technique used is very simple and is not expected to work for all canopies and sky illumination conditions. The automation is only there to give reasonable thresholds that should always be modified by the user. The manually found $\mathrm{DN}_{\text {Min values were on }}$ average 30 DNs larger than the ones determined by the software, indicating that a better estimate could be found by adding more than 30 intensity levels to the $\mathrm{DN}_{\mathrm{Min}}$ found automatically. $\mathrm{DN}_{\mathrm{Max}}$ values were about 10 levels smaller than that found by the operator. Nevertheless, even with differences of 30 levels for the low threshold and 10 levels for the high threshold, the 

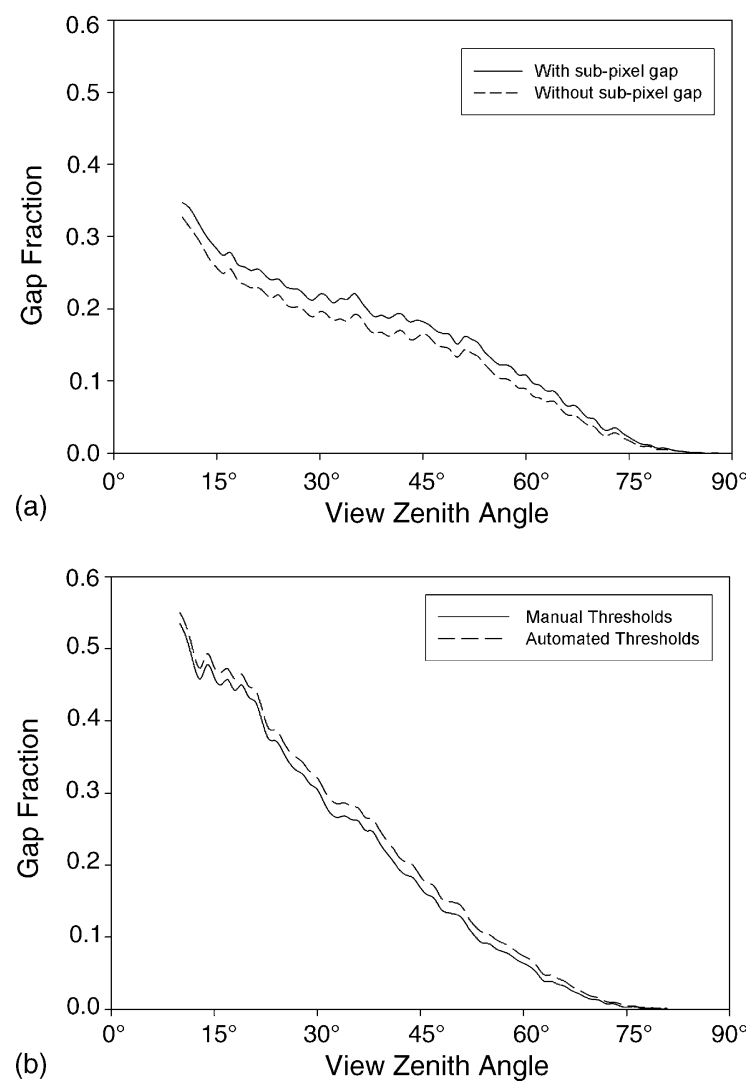

Fig. 5. Gap fraction of (a) deciduous stand from Larose (plot D1) without sub-pixel gaps; and (b) a 72-year-old black spruce stand near Thompson, Manitoba (plot T4), with different thresholds.

effect on the retrieval is small: the gap fraction is changed by about $7 \%$ relatively for small view zenith angle and can be relatively large at large zenith angle, but the difference in absolute values is small (e.g. less than 0.0005 for Fig. 5b).

\subsection{DHP clumping index retrieval}

Fig. 6a and $\mathrm{b}$ show accumulated gap fraction profiles from plot T04. The measured $\left(F_{\mathrm{m}}\right)$, reduced $\left(F_{\mathrm{mr}}\right)$ and theoretical random $\left(F_{\mathrm{r}}\right)$ curves are plotted against the gap size in pixel unit. The measured curves are as smooth as what it is normally measured with TRAC on transect of $60 \mathrm{~m}$ and more. This is achieved by using multiple photographs per plots. Our results indicate that four to six photographs per plot are generally needed to achieve consistent results. The
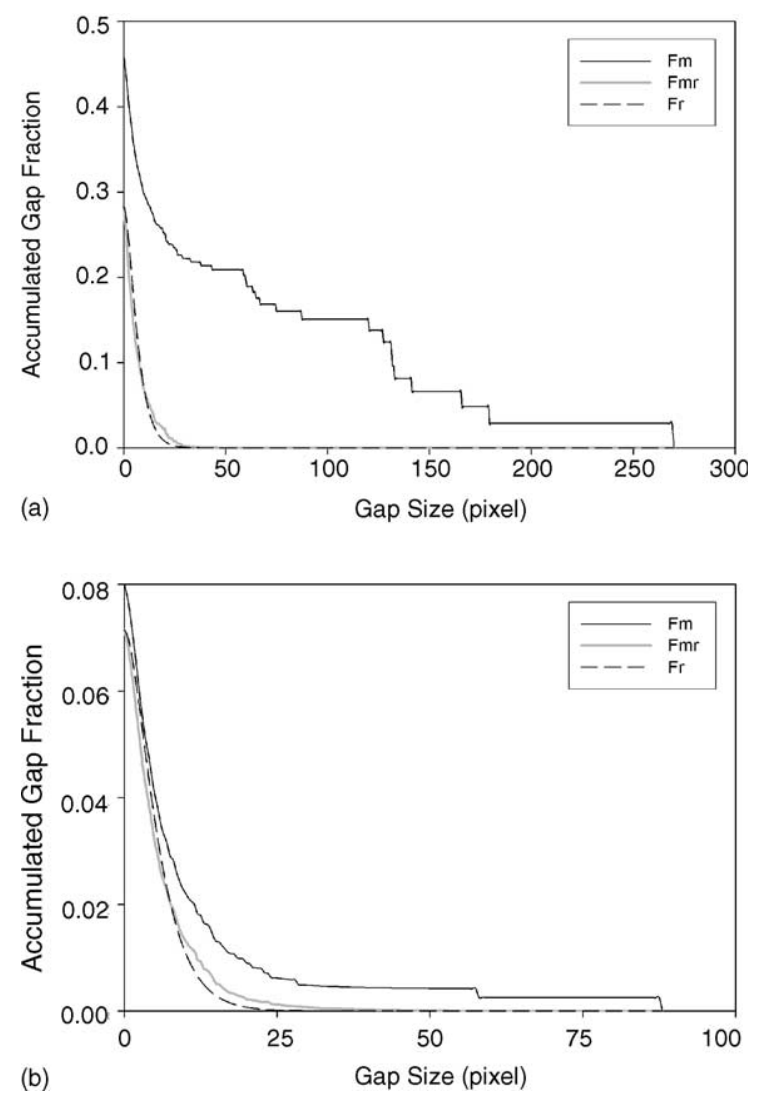

Fig. 6. The measured $\left(F_{\mathrm{m}}\right)$, reduced $\left(F_{\mathrm{mr}}\right)$, and theoretical random $\left(F_{\mathrm{r}}\right)$ accumulated gap size distributions based on 11 photographs from the 72-year-old black spruce plot (T04) for (a) vza $=10^{\circ}$ and (b) $\mathrm{vza}=57^{\circ}$.

number of photographs is especially important for view angles closer to the zenith that are under sampled. The profile at view zenith angle $57^{\circ}$ (Fig. 6b) is smoother than the one at $10^{\circ}$ (Fig. 6a) and corresponds to an almost perfect random foliage distribution.

To reduce the $F_{\mathrm{m}}$ curves, the projected foliage element width, $W_{\mathrm{p}}(\theta)$, is required to get the theoretical $F_{\mathrm{r}}$ curves. The retrieval of the element width is assessed in Fig. 7a-c. The $W_{\mathrm{p}}(\theta)$ curves generally follows the $1 / \cos \theta$ behaviour predicted by the theory (Chen and Cihlar, 1995a). The mean element width is the value at which the curves go at the zenith. It is one pixel for the deciduous stand D1 from Fig. 8a and about $1 / 4$ of a pixel for the black spruce in Fig. $8 b$ and c.

The addition of sub-pixel gaps to the analysis did not alter much the angular properties of $W_{\mathrm{p}}(\theta)$ in the deciduous plot D1 as shown in Fig. 7a. The $W_{\mathrm{p}}(\theta)$ 

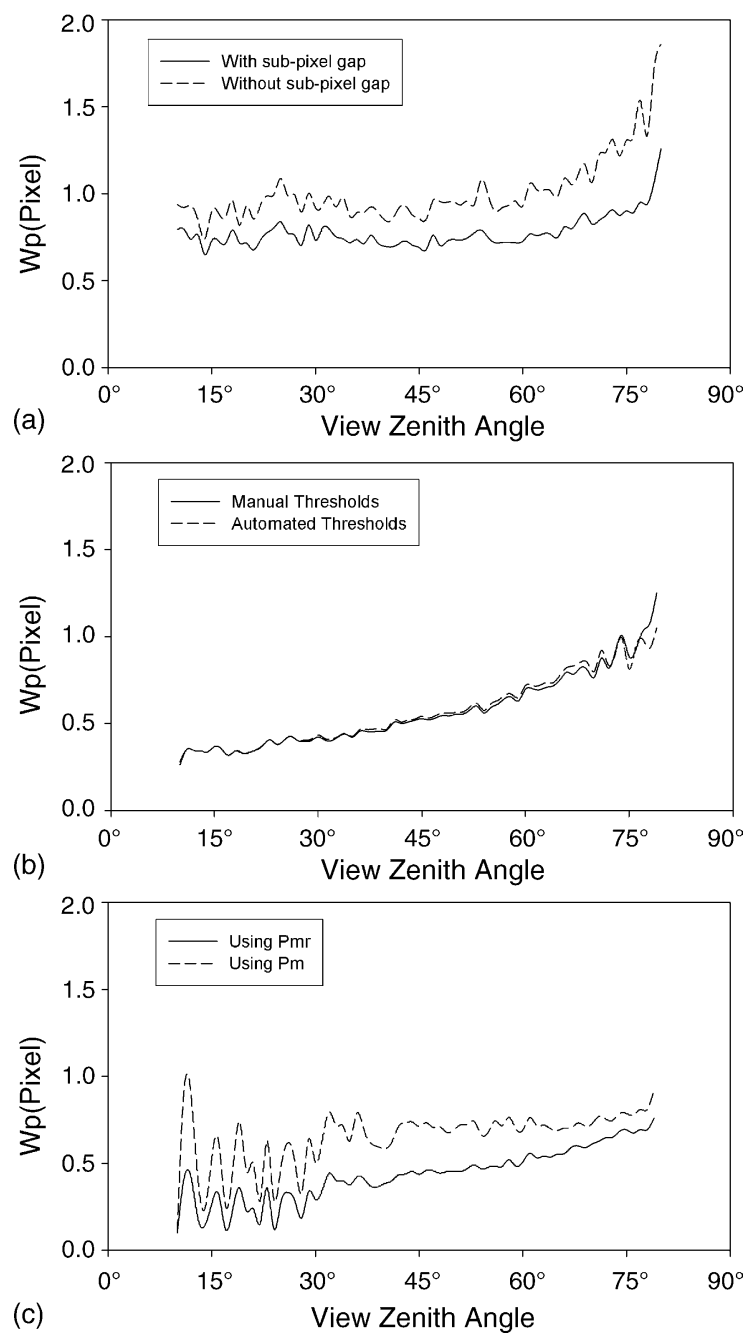

Fig. 7. Element size $W_{\mathrm{p}}(\theta)$ in pixel size unit based on the " $P$ " approach of Chen and Black (1992a, b). (a) From Larose stand D1; (b) for T04 with different thresholds; and (c) plot T01, with $\left(P_{\mathrm{mr}}\right)$ and without $\left(P_{\mathrm{m}}\right)$ iterations to find $W_{\mathrm{p}}(\theta)$.

retrieval for this plot is constant up to a view zenith angle of $75^{\circ}$. The thresholding difference of $30 \mathrm{DNs}$ for low thresholds and 10 DNs for high thresholds presented earlier had a negligible effect on the retrieval of $W_{\mathrm{p}}(\theta)$ for plot T04 (Fig. 7b). The retrieval using the iteration method $\left(P_{\mathrm{mr}}\right)$ gives smaller $W_{\mathrm{p}}(\theta)$ values and less noisy result (Fig. 7c) than from $P_{\mathrm{m}}$. Although the two black spruce plots, T01 (Fig. 7c) and T04 (Fig. 7b) are very different, T04 being much denser than T01, they exhibit similar projected element width profile.
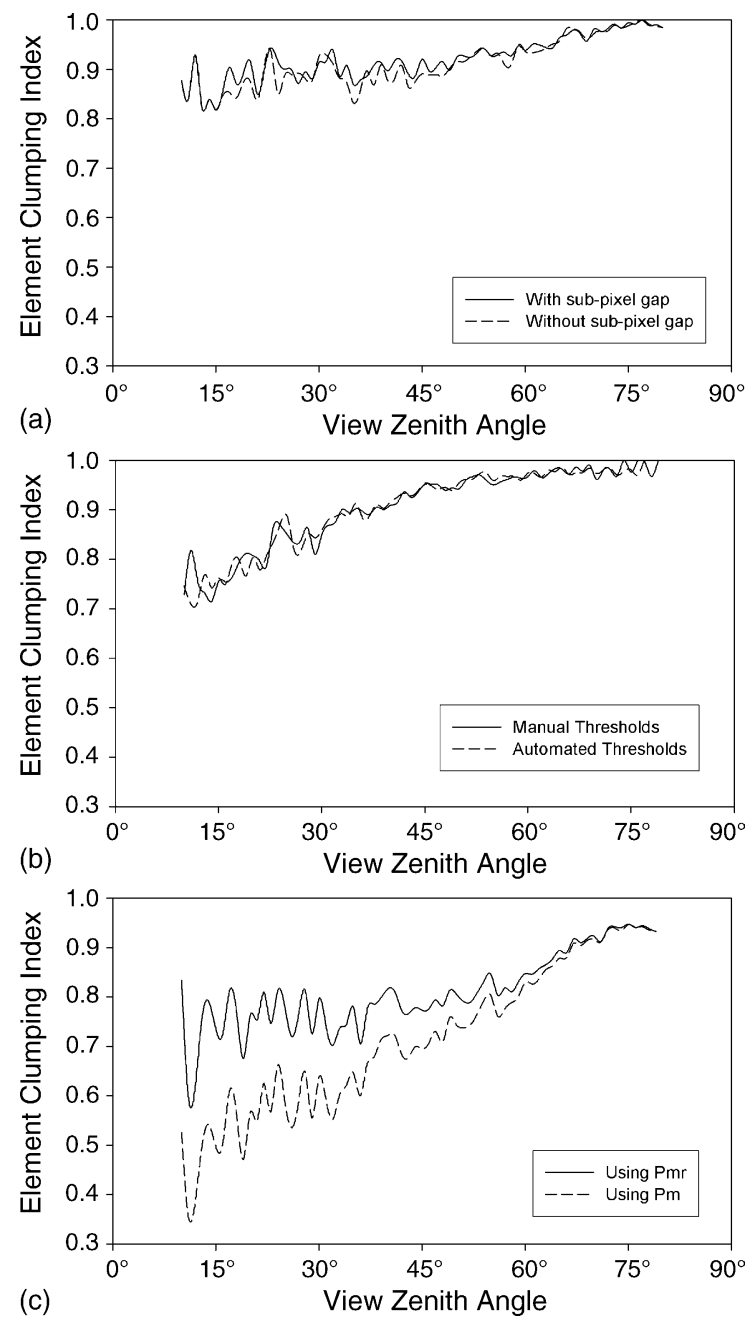

Fig. 8. Clumping Index (CC method) measured every one degree in zenith for (a) Larose D1 stand; (b) the 72-year-old black spruce stand (T04); and (c) open black spruce stand T01, with $\left(P_{\mathrm{mr}}\right)$ and without $\left(P_{\mathrm{m}}\right)$ iterations to find $W_{\mathrm{p}}(\theta)$.

Fig. 8a-c show the clumping index variation with zenith angle from the three plots: D1, T04, and T01, respectively. The general trend is that clumping index increase with view zenith angle as suggested by Kucharik et al. (1997). As with previous figures, each profile is plotted showing different aspects that can affect the results. The clumping index retrieval is directly related to the element width retrieval. Plot T01 (Fig. 9c) is shown with effect on $W_{\mathrm{p}}(\theta)$ because the openness of a canopy greatly affects $W_{\mathrm{p}}(\theta)$ and T01 is the most open of the stand presented in this paper. In 


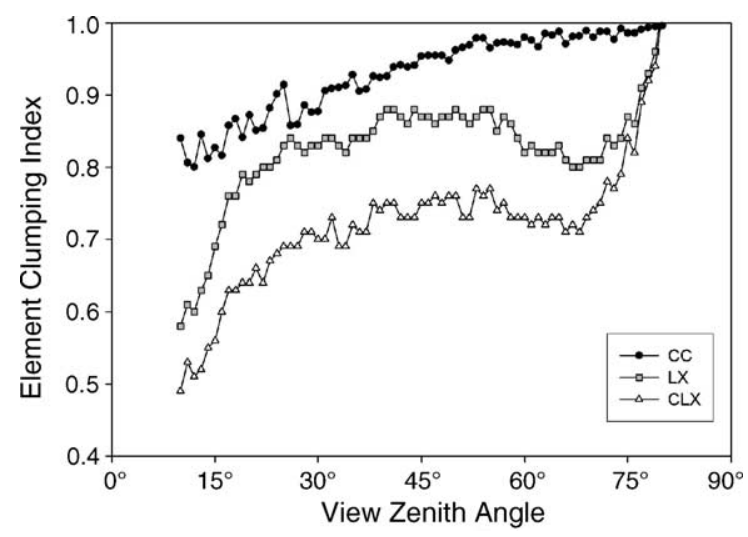

Fig. 9. Clumping index measured at every $1^{\circ}$ in zenith for a 72 -yearold black spruce stand using different techniques: (CC) Chen and Cihlar (1995a, b) gap size distribution; (LX) Lang and Xiang logarithm averaging; and (CLX) a combination of CC and LX.

general, the profile is more scattered at view zenith angles less than $30^{\circ}$. The effect of the iteration was to diminish the large clumping index decrease near the zenith, indicating that the clumping index may be near constant for large range of view zenith in some stands.

Fig. 9 shows clumping index variations with view zenith angle, using the three methods described earlier, extracted from 13 photographs taken every $10 \mathrm{~m}$ on a 120 -m East-West transect in a 72-year-old black spruce stand near Thompson, Manitoba (plot T04). The three methods gave consistent angular variation in the range of zenith angle $30-60^{\circ}$. This is within the normal useable range for the three methods, depending on the number of photographs and canopy foliage density. Some cases may allow the retrieval for a larger range than $30-60^{\circ}$, especially the $\mathrm{CC}$ method that does not show radical changes outside that range as oppose to the other two methods. The LX and CLX methods have problems because of the denser segments and the sub-pixel gap used. This allows very small gaps fraction for a given segment. We artificially altered the segments that had gap fraction less than half a pixel to be half a pixel, but it still seems to exaggerate the retrieved LAI values.

\subsection{Foliage projection}

The foliage projection coefficient $G(\theta)$ can be greatly influenced by the clumping index retrieval. We

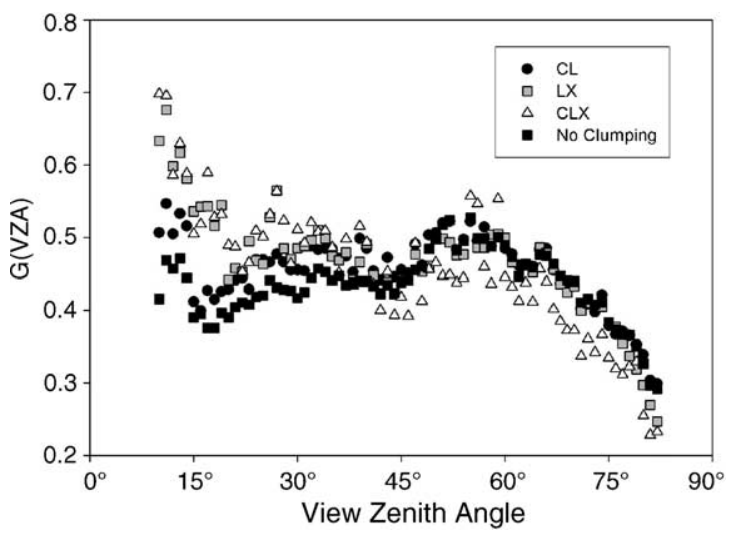

Fig. 10. Foliage projection coefficient $G(\theta)$ profiles from the Siberian stand K2.2 using different techniques: (CC) Chen and Cihlar (1995a,b) gap size distribution; (LX) Lang and Xiang logarithm averaging; (CLX) a combination of CC and LX; and without clumping consideration.

showed how different clumping index profiles, from plot K2.2 could affect its retrieval in Fig. 10. For that plot, the LX and CLX methods induced very small clumping index at small view zenith angles. The effect on $G(\theta)$ implies that a much more erectophile behavior for this particular plot is found compared with the CL method or without clumping consideration (i.e. $\Omega(\theta)=1)$. Overall in the $30-60^{\circ}$ range, the clumping index retrieval methods used do not alter much $G(\theta)$ and seems to be randomly distributed (i.e. $G(\theta) \sim 0.5$ in that range).

\subsection{Plant area index}

We examine here the difference in plant area index for plots D1, T04 and T01, due to different assumptions and processing methods. Using the gap fraction and clumping index profiles extracted at every $1^{\circ}$, from view zenith angle $10-80^{\circ}$, plots D1, T04, and T01's PAI are estimated at 2.45, 2.49 and 1.24, respectively. The difference in thresholding between the operator and the program DHP.exe had a very small effect of only $1 \%$ on T04's PAI, from 3.49 to 3.54. The effect of different $W_{\mathrm{p}}(\theta)$ retrieval gave a $9 \%$ difference. When all pixels with sub-gaps are assumed to be canopy pixels, which can be seen as the worst thresholding error possible, it gave an $8 \%$ increase in PAI. It is expected that human operators can find the thresholds within \pm 10 DNs under diffuse sky 
conditions so that the difference due to thresholding errors is negligible when using the two-threshold method. Although the clumping index zenithal profiles are noisy, a clear trend can be seen and equations suggested by Kucharik et al. (1997) can be used to model the curves.

Comparisons between different instruments used to estimate LAI are usually done at the resulting LAI level, i.e. after the logarithmic transformation of the gap fraction (e.g. Chen et al., 1997; Frazer et al., 2001). Comparisons at the gap fraction level are rare but also essential for a good understanding of the potential differences between sensors. A good range of gap fraction values, from 0.1 to 0.8 , was measured with TRAC for this study. This allows a wide range for comparison with the digital camera estimates. Fig. 11a shows a comparison between TRAC derived gap fraction, measured at the acquisition time solar zenith angle, with the cameras derived gap fraction at the view zenith angle equivalent to the TRAC solar zenith angle. The two instruments gap fraction estimates are different, but consistent, with a root mean squared error (R.M.S.E.) of 0.14. However, they are well correlated with a coefficient of determination $R^{2}$ of $0.91 \quad[P(\mathrm{DHP})=1.13 \times P(\mathrm{TRAC})+0.02]$. Once transformed in effective plant area index, the R.M.S.E. is $0.76\left(\mathrm{~m}^{2} / \mathrm{m}^{2}\right)$. Differences between the two sensors were expected because:

(1) TRAC has problems measuring very small gaps about less than half the sun angular field of view (Kucharik et al., 1997);

(2) digital photographs can suffer from chromatic aberration and blooming that makes canopy pixels that are near sky pixels appear brighter than they really are.

To verify these hypotheses, the DHP gap fraction is recalculated without sub-pixel gap. Fig. $11 \mathrm{~b}$ shows the same TRAC measurements of gap fraction as Fig. 11a, but all the DHP mixed pixels as set to foliage pixels, i.e. all sub-pixel gap fraction set to zero. This allows the one-to-one line to be within the $95 \%$ confident interval of the data. The R.M.S.E is down to 0.08 for the gap fraction with a slightly higher $R^{2}$ of 0.94 . In term of effective PAI, the R.M.S.E is down to $0.35\left(\mathrm{~m}^{2} / \mathrm{m}^{2}\right)$.

This test has two effects: it removes all small gaps in the DHP and it reduces the size of gaps that may
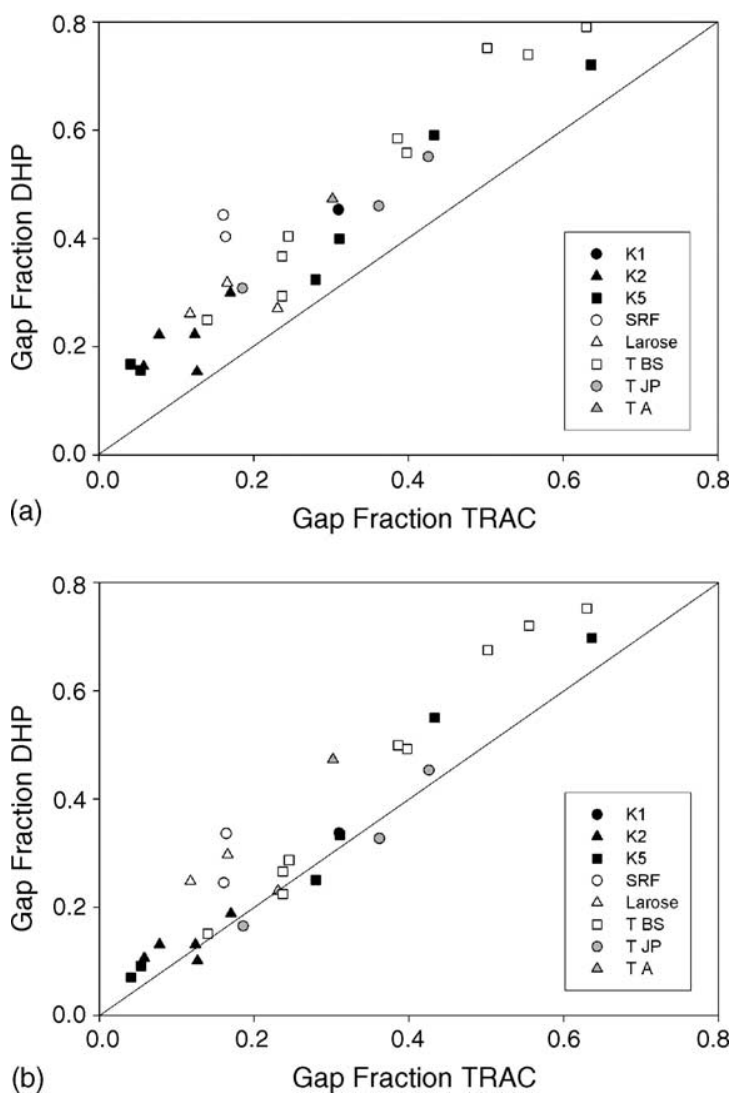

Fig. 11. comparison of TRAC and DHP gap fraction for all sites visited, (a) using DHP sub-pixel gap fraction and (b) all DHP gap smaller than one pixel are assumed to be canopy pixels. K1, K2, and K5 are from Siberian sites, SRF from Smooth Rock Falls, Larose from Larose Forest near Ottawa, TBS, TJP and TA, for black spruces, jack pine and aspen sites near Thompson.

have been incorrectly measured due to blooming. The TRAC processing has been developed to measure gaps smaller than the angular solar disc (Chen, 1996b), but the choice of minimum PPFD value that changes due to the amount of diffused light under the canopy could prevent very small gaps to be measured, i.e. small gaps may have lower PPFD than the diffused light. However, even when considering this potential problem in some TRAC segments, it cannot account for the large difference found in Fig. 11a. One assumption used in the sub-pixel calculation is that light only comes perpendicularly for each camera pixel. This is a good approximation under dense canopies, but may not hold for open canopies where 
large gaps allow light to reach the canopy from more directions.

The large gap fraction found in one of the Krasnoyarsk sites is closer to the one-to-one line than many of the Thompson black spruce stands. This is unexpected since the sky conditions were not optimal for fish-eye photography with broken clouds in midafternoon for Krasnoyarsk while the Thompson photographs were all taken under diffuse conditions. One of the points further from the one-to-one line in Fig. $11 \mathrm{~b}$ is from Smooth Rock Fall. The sunny condition and openness of the site are the most probable cause of this large discrepancy. The DHP gap fraction under other sunny conditions was closer to that of TRAC, but the openness of the Smooth Rock Fall plots allowed a large quantity of solar radiation to enter directly into the canopy and be scattered to the camera, making some foliage pixels look like gaps. This is because the thresholding method, which assumes that the irradiance is independent of the azimuth, does not work for sunny conditions. Leblanc and Chen (2001) showed that at low LAI values, most view zenith angles were affected by the increase in radiance reaching the sensor due to light scattering. The problem with two of the Larose points may be due to blooming since the photographs taken show clearly that foliage elements are missing, especially near the zenith. Three of the plots (T06, T12 and T13) had low quality TRAC measurements. It may also have contributed to the gap fraction difference since the maximum PPFD were very low (less than $1000 \mu \mathrm{mol} / \mathrm{m}^{2} / \mathrm{s}$ ), indicating that the sky was not perfectly clear, which usually causes the gap fraction to be underestimated.

Fig. 12 shows that overall, the clumping index, using the $\mathrm{CC}$ method, from TRAC does not agree with the clumping index from the digital hemispherical photography. This may be explained by the sampling schemes used for each plot. Three sampling schemes were used in the data presented here (see Table 4):

(1) $25 \mathrm{~m} \times 25 \mathrm{~m}$ plots with six photographs and 2 or 6 TRAC transects,

(2) long linear transects with photographs every $20 \mathrm{~m}$ and

(3) long linear transects with photographs every $10 \mathrm{~m}$.

The last two schemes should have been the same with photographs every $10 \mathrm{~m}$, but technical problems

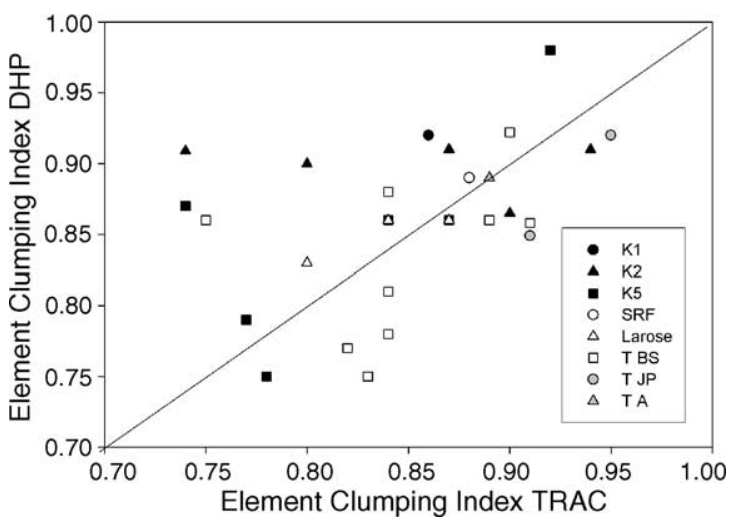

Fig. 12. Comparison between the clumping index from TRAC at the solar zenith angle with the element-clumping index at the same zenith angle from digital hemispherical photography. Symbols are the same as Fig. 11.

forced us to reduced the number of photographs for a few days. The third method, with sampling every $10 \mathrm{~m}$ on linear transect gave the best mean absolute relative difference at $4 \%$, all plots under $10 \%$. The under sampling of the scheme with photographs every $20 \mathrm{~m}$ gave relative difference between 5 and $15 \%$, with a mean of $9 \%$, and similar numbers can be found when removing photographs in the third method. The cases of the $25 \mathrm{~m} \times 25 \mathrm{~m}$ plots gave very good and bad results, with a mean of $8 \%$. This can be attributed to stand conditions that were not always the same within and immediately outside the plots. This suggests that the TRAC derived clumping index may not be adequate for correction of effective PAI derived from fisheye devices when the stand variability is large. It may still be appropriate to correct the plant canopy analyser LAI-2000 measurements if a view cap is used and the instrument is used looking at the same direction as the TRAC measured solar sunflecks. Neither TRAC nor the digital hemispherical photography clumping indices are necessary wrong, they just represent different parts of the stand and shows that the clumping index is more variable than the gap fraction and thus requires a larger sampling. It must be noted that the digital cameras retrieved clumping index is very constant for the Krasnoyarsk conifer plots (see Fig. 12), all, but one, retrieved values are near 0.90 while TRAC retrieved values are more variable. TRAC measurements may represent better the different plot conditions while the larger footprint $\left(360^{\circ}\right.$ in azimuth) of the he- 
Table 4

Results from different boreal plots

\begin{tabular}{|c|c|c|c|c|c|c|c|c|c|c|c|c|}
\hline Plot name & Species & PAIe & $\Omega_{\mathrm{CC}}$ & PAIcc & $\Omega_{\mathrm{LX}}$ & $\mathrm{PAI}_{\mathrm{LX}}$ & $\Omega_{\mathrm{CLX}}$ & PAI $_{\text {CLX }}$ & $\begin{array}{l}\text { Crown } \\
\text { closure }\end{array}$ & $\begin{array}{l}\text { Sky } \\
\text { condition }\end{array}$ & $\begin{array}{l}\text { Camera } \\
\text { points }\end{array}$ & $\begin{array}{l}\text { TRAC } \\
\text { transect }(\mathrm{m})\end{array}$ \\
\hline D1 & MD & 2.29 & 0.95 & 2.4 & 0.79 & 2.9 & 0.69 & 3.3 & 0.60 & $\mathrm{DC}$ & 10 & $1 \times 90$ \\
\hline D2 & MD & 1.85 & 0.94 & 2.0 & 0.80 & 2.3 & 0.68 & 2.7 & 0.67 & DC & 8 & $1 \times 70$ \\
\hline K1.3 & MC & 0.90 & 0.94 & 1.0 & 0.95 & 1.0 & 0.81 & 1.1 & 0.34 & DD & 6 & $2 \times 25$ \\
\hline K2.1 & $\mathrm{MC}$ & 3.00 & 0.96 & 3.1 & 0.83 & 3.6 & 0.72 & 4.1 & 0.66 & $S$ & 6 & $6 \times 25$ \\
\hline $\mathrm{K} 2.2$ & $\mathrm{MC}$ & 3.10 & 0.97 & 3.2 & 0.84 & 3.7 & 0.67 & 4.7 & 0.73 & $S$ & 6 & $2 \times 25$ \\
\hline K2.3 & MC & 2.10 & 0.92 & 2.3 & 0.80 & 2.6 & 0.64 & 3.2 & 0.53 & S & 6 & $6 \times 25$ \\
\hline K2.4 & $\mathrm{MC}$ & 2.10 & 0.94 & 2.2 & 0.85 & 2.4 & 0.75 & 2.7 & 0.68 & S & 6 & $2 \times 25$ \\
\hline K2.5 & $\mathrm{MC}$ & 2.10 & 0.92 & 2.3 & 0.84 & 2.5 & 0.72 & 2.9 & 0.51 & S & 6 & $2 \times 25$ \\
\hline K5.1 & A & 2.57 & 0.99 & 2.6 & 0.91 & 2.8 & 0.83 & 3.1 & 0.74 & DC & 6 & $2 \times 25$ \\
\hline K5.2 & MD & 0.57 & 0.80 & 0.6 & 0.71 & 0.8 & 0.57 & 1.0 & 0.22 & $\mathrm{BC}$ & 6 & $2 \times 25$ \\
\hline K5.3 & MD & 1.15 & 0.89 & 1.3 & 0.75 & 1.5 & 0.63 & 1.8 & 0.29 & $\mathrm{BC}$ & 6 & $2 \times 25$ \\
\hline K5.4 & MD & 1.24 & 0.91 & 1.4 & 0.79 & 1.6 & 0.68 & 1.8 & 0.56 & $\mathrm{BC}$ & 6 & $2 \times 25$ \\
\hline K5.5 & MD & 1.89 & 0.89 & 2.1 & 0.74 & 2.6 & 0.64 & 3.0 & 0.66 & $\mathrm{BC}$ & 25 & $1 \times 240$ \\
\hline K5.6 & MD & 0.64 & 0.79 & 0.8 & 0.60 & 1.1 & 0.51 & 1.3 & 0.27 & $\mathrm{BC}$ & 25 & $1 \times 240$ \\
\hline SRF01 & MCD & 1.09 & 0.89 & 1.2 & 0.76 & 1.4 & 0.65 & 1.7 & 0.15 & $\mathrm{~S}$ & 7 & $1 \times 60$ \\
\hline SRF02 & MCD & 1.90 & 0.89 & 2.1 & 0.67 & 2.8 & 0.58 & 3.3 & 0.47 & S & 8 & $1 \times 60$ \\
\hline T01 & BS & 1.14 & 0.83 & 1.4 & 0.69 & 1.6 & 0.57 & 2.0 & 0.14 & DD & 9 & $1 \times 160$ \\
\hline T02 & $\mathrm{BS}$ & 1.10 & 0.83 & 1.4 & 0.70 & 1.6 & 0.60 & 1.9 & 0.27 & DD & 10 & $1 \times 180$ \\
\hline T03 & BS & 1.30 & 0.90 & 1.4 & 0.82 & 1.5 & 0.72 & 1.8 & 0.32 & DD & 14 & $1 \times 260$ \\
\hline T04 & BS & 2.60 & 0.97 & 2.7 & 0.85 & 3.1 & 0.74 & 3.5 & 0.45 & DD & 13 & $1 \times 120$ \\
\hline T05 & BS & 0.60 & 0.74 & 0.9 & 0.83 & 0.8 & 0.62 & 1.0 & 0.08 & DD & 9 & $1 \times 80$ \\
\hline T06 & BS & 1.20 & 0.86 & 1.4 & 0.80 & 1.5 & 0.64 & 1.9 & 0.44 & DD & 13 & $1 \times 120$ \\
\hline T07 & BS & 0.60 & 0.77 & 0.8 & 0.79 & 0.8 & 0.61 & 1.0 & 0.10 & DD & 11 & $1 \times 100$ \\
\hline T08 & BS & 1.80 & 0.93 & 1.9 & 0.78 & 2.3 & 0.62 & 2.9 & 0.41 & DD & 8 & $1 \times 70$ \\
\hline T09 & $\mathrm{JP}$ & 1.30 & 0.87 & 1.6 & 0.68 & 2.0 & 0.57 & 2.4 & 0.29 & DD & 6 & $1 \times 100$ \\
\hline $\mathrm{T} 10$ & JP & 1.62 & 0.95 & 1.7 & 0.85 & 1.9 & 0.71 & 2.3 & 0.53 & DD & 8 & $1 \times 140$ \\
\hline $\mathrm{T} 11$ & JP & 0.82 & 0.91 & 0.9 & 0.91 & 0.9 & 0.77 & 1.0 & 0.25 & DD & 11 & $1 \times 100$ \\
\hline $\mathrm{T} 12$ & A & 1.19 & 0.97 & 1.2 & 0.92 & 1.3 & 0.83 & 1.4 & 0.47 & DD & 10 & $1 \times 90$ \\
\hline T13 & MCD & 0.77 & 0.86 & 0.9 & 0.75 & 1.0 & 0.63 & 1.2 & 0.07 & DD & 11 & $1 \times 60$ \\
\hline
\end{tabular}

Species: MD, mixed deciduous; MC, mixed coniferous; A, aspen; BS, black spruce; JP, jack pine; and MCD, mixed deciduous-coniferous. Sky condition: DC, diffused cloud; S, sunny; BC, broken clouds; DD, dusk diffused.

mispherical photographs probably tends to average the conditions to a value that may be more representative of the whole stand than each plot.

\subsection{Leaf area index}

The first goal of this study was to show that fish-eye lenses mounted on digital camera could be used to measure the same quantities as previously used instruments such as TRAC and not to compare the retrieved LAI with any "true" LAI such as destructive or allometric LAI. However, any method is only as good as its ability to reproduce values from methods that are considered the most accurate. Two of our plots near Thompson were established in plots made by a group from the University of Wisconsin for a chronosequence study (Bond-Lamberty et al., 2002). Plot T04 in our study corresponds to their plot D1930 and plot T13 corresponds to plot D1964.

To obtain LAI, local values of needle-to-shoot ratio and woody material are needed. The two plots are within the BOREAS experiment area where numerous measurements were taken. Averaged needle-to-shoot and woody to total ratio values from BOREAS black spruce stands are used. The D1930 LAI from allometric regression was 6.8. Using the mean value of 1.4 for the black spruce needle-to-shoot area ratio (Chen et al., 1997) and 0.15 for woody to total ratio (Chen et al., 1997; Gower et al., 1997, 1999) with the digital hemispherical photography derived effective PAI (2.7), the LAI found is 3.3 with the clumping index of 0.97 found with the $\mathrm{CC}$ method at $57.3^{\circ}$, a 
$50 \%$ difference. It is 3.7 and 4.2 using the LX and CLX methods, respectively. If the DHP gap fraction is normalized to the TRAC value, the LAI would be 4.2 , 4.3, and 4.8 using the CC, LX and CLX methods, respectively.

For T13, the allometric LAI is 1.8 , while the optically derived LAI is 1.0 using a needle-to-shoot area ratio of 1.35 (mix of black spruces, jack pines, and some aspens) and woody-to-total area ratio of 0.15 , again a $50 \%$ difference. It would have been 1.1 and 1.4 using the LX and CLX clumping index, respectively. The LAI based on the DHP normalized to TRAC measurements are: $1.2,1.4$, and 1.7 for the CC, LX and CLX methods, respectively.

Generally, the CLX methods gave better results when compared to the allometric LAI. The mixed stand gave very good results, but black spruce stands are known to be amongst the most clumped stands and are difficult to be measured accurately with optical instruments (Chen et al., 1997). The CLX method is similar to the combined LAI-2000 and TRAC method of Chen et al. (1997) where the clumping index is found with TRAC and a logarithm average of the gap fraction is done over the LAI-2000 data. Retrieval of LAI using the combination of TRAC and LAI-2000 by Chen et al. (1997) was comparable to allometric LAI in most canopies, except the southern old black spruce stand of BOREAS. In such stands, the measured quantity is more a crown area index as the opacity of some portion of tree crowns prevents any light to go through them (Nilson, 1999).

\section{Conclusions}

We showed that the plant area index and clumping index can be retrieved using only fish-eye photographs; cutting down the cost of instrumentation needed and the accuracy is expected to increase, as the digital camera technology improves. Considering the combined costs of the LAI-2000 and TRAC, a system with on off-the-shelf digital camera with a fish-eye lens is a low-cost alternative. New digital cameras with better spatial radiometric resolutions are constantly made available for the same price as current cameras. Gap fraction measurements made with TRAC and from digital hemispherical photography are well correlated, with a bias attributed to light scattering effects on the photographs and by TRAC inability to see very small gaps. Different sampling schemes of the canopy may have contributed to the poor agreement for the clumping index retrieved with TRAC and digital hemispherical photography. The LAI estimated from DHP using clumping index from the CC and LX methods with typical values for the needle-to-shoot ratio and the woody-to-total area ratio underestimated the allometric measurements from two boreal forest stands, but the combined method (CLX) gave results closer to the allometric method. This later method should be investigated in more details in order to solve its difficulty in dense area of canopies.

The Microsoft Windows-based programs DHP.exe and TRACWin.exe that were used for the analysis in this paper are available freely from the corresponding author.

\section{Acknowledgement}

The authors would like to thank A. Bezduganova, B. Bond-Lamberty, Y. Gorbounova, S.T. Gower, A. Hill, A. Nelzina, R. Latifovic, L. Vierling and S. Wang for assistance in the field data collection, G. Frazer and R. Fournier for discussions on fish-eye lenses and data collection, the two anonymous reviewers for their constructive comments, and R. Gauthier and H.P. White who reviewed the paper internally before submission.

\section{References}

Asner, G.P., Scurlock, J.M.O., Hicke, J.A., 2003. Global synthesis of leaf area index observations: implications for ecological and remote sensing studies. Global Ecol. Biogeogr. 12, 191-205.

Baret, F., Andrieu, B., Folmer, J.C., Hanocq, J.F., Sarrouy, C., 1993. Gap fraction measurement using hemispherical infrared photographies and its use to evaluate PAR interception efficiency. In: Varlet-Grancher, C., Bonhomme, R., Sinoquet, H. (Eds.), Crop structure and light microclimate: characterization and applications. INRA, Paris, pp. 359-372.

Bicheron, P., Leroy, M., 1999. A method of biophysical parameter retrieval at global scale by inversion of a vegetation reflectance model. Remote Sens. Environ. 67, 251-266.

Bond-Lamberty, B., Wang, C., Gower, S.T., Norman, J., 2002. Leaf area dynamics of a boreal black spruce fire chronosequence. Tree Physiol. 22, 993-1001.

Brenner, A.J., Ceuto Romero, M., Garcia Haro, J., Gilabert, M.A., Incoll, L.D., Martinez Fernandez, J., Porter, E., Pugnaire, F.I., Younis, M.T., 1995. A comparison of direct and indirect methods 
for measuring leaf and surface areas of individual bushes. Plant Cell Environ. 18, 1332-1340.

Canham, C.D., 1988. An index for understory light levels in and around canopy gaps. Ecology 69, 1634-1638.

Chen, J.M., 1996a. Optically-based methods for measuring seasonal variation in leaf area index of boreal conifer forests. Agric. Forest Meteorol. 80, 135-163.

Chen, J.M., 1996b. Canopy architecture and remote sensing of the fraction of photosynthetically active ration absorbed by boreal conifer forests. IEEE Trans. Geosci. Remote Sens. 34, 13531368 .

Chen, J.M., Black, T.A., 1992a. Defining leaf area index for non-flat leaves. Plant Cell Environ. 15, 421-429.

Chen, J.M., Black, T.A., 1992b. Foliage area and architecture of clumped plant canopies from sunfleck size distributions. Agric. Forest Meteorol. 60, 249-266.

Chen, J.M., Black, T.A., Adams, R.S., 1991. Evaluation of hemispherical photography for determining plant area index and geometry of a forest stand. Agric. Forest Meteorol. 56, 129-143.

Chen, J.M., Cihlar, J., 1995a. Plant canopy gap-size analysis theory for improving optical measurements of leaf area index. Appl. Optics 34 (27), 6211-6222.

Chen, J.M., Cihlar, J., 1995b. Quantifying the effect of canopy architecture on optical measurements of leaf area index using two gap size analysis methods. IEEE Trans. Geosci. Remote Sens. 33, 777-787.

Chen, J.M., Rich, P.M., Gower, S.T., Norman, J.M., Plummer, S., 1997. Leaf area index of boreal forests: theory, techniques, and measurements. J. Geophys. Res. 102 (D24), 29429-29443.

Chen, J.M., Pavlic, G., Brown, L., Cihlar, J., Leblanc, S.G., White, H.P., Hall, R.J., Peddle, D., King, D.J., Trofymow, J.A., Swift, E., Van der Sanden, J., Pellikka, P., 2002. Derivation and validation of Canada-wide coarse resolution leaf area index maps using high-resolution satellite imagery and ground measurements. Remote Sens. Environ. 80, 165-184.

Chen, J.M., Liu, J., Leblanc, S.G., Lacaze, R., Roujean, J.-L., 2003. A demonstration of the utility of multi-angle remote sensing for estimating carbon absorption by vegetation. Remote Sens. Environ. 84, 516-525.

Clearwater, M.J., Gould, K.S., 1995. Leaf orientation and light interception by juvenile Pseudopanax crassifolius (Cunn.) C. Koch in a partially shaded forest environment. Oecologia (Berlin) 104 (3), 363-371.

Digital Photography Review, 2003. http://www.dpreview.com/ (accessed July 17, 2003).

Englund, S.R., O’Brien, J.J., Clark, D.B., 2000. Evaluation of digital and film hemispherical photography and spherical densiometry for measuring forest light environments. Can. J. Forest Res. 30, 1999-2005.

Fassnacht, K., Gower, S.T., Norman, J.M., McMurtrie, R.E., 1994. A comparison of optical and direct methods for estimating foliage surface area index in forests. Agric. Forest Meteorol. 71, 183207.

Fernandes, R., White, H.P., Leblanc, S.G., Pavlic, G., McNairn, H., Chen, J.M., King, D., Seed, E., Olthof, I., Hall, R., Examination of error propagation in relationships between leaf area index and spectral vegetation indices from Landsat TM and ETM. 23rd CSRS, Quebec City, August 21-24, 2001.

Fernandes, R., Butson, C., Leblanc, S.G., Latifovic, R., 2003. Landsat-5 TM and Landsat-7 ETM+ based accuracy assessment of leaf area index products for Canada derived from SPOT-4 VEGETATION data. Can. J. Remote Sens. 9 (2), 241-258.

Fournier, R.A., Landry R., August, N.M., Fedosejevs, G., Gauthier, R.P., 1996. Modelling light obstruction in three conifer forests using hemispherical photography and fine tree architecture. 82, 47-72.

Frazer, G.W., Canham, C.D., Lertzman, K.P., 1999. Gap Light Analyzer (GLA): Imaging software to extract canopy structure and gap light transmission indices from true-colour fisheye photographs, users manual and program documentation. Copyright (C) 1999: Simon Fraser University, Burnaby, British Columbia, and the Institute of Ecosystem Studies, Millbrook, New York.

Frazer, G.W., Trofymow, J.A., Lertzman, K.P., 2000. Canopy openness and leaf area in chronosequences of coastal temperate rainforests. Can. J. Forest Res. 30, 239-256.

Frazer, G.W., Fournier, R.A., Trofymow, J.A., Hall, J.R., 2001. A comparison of digital and film fisheye photography for analysis of forest canopy structure and gap light transmission. Agric. Forest Meteorol. 109, 249-263.

Gower, S.T., Vogel, J.G., Norman, J.M., Kucharik, C.J., Steele, S.J., Stow, T.K., 1997. Carbon distribution and aboveground net primary production in aspen, jack pine, and black spruce stands in Saskatchewan and Manitoba, Canada. J. Geophys. Res. 102 (D24), 29029-29041.

Gower, S.T., Kucharik, J.K., Norman, J.M., 1999. Direct and indirect estimation of leaf area index, fapar, and net primary production of terrestrial ecosystems. Remote Sens. Environ. 70, 29-51.

Hale, S.E., Edwards, C., 2002. Comparison of film and digital hemispherical photography across a wide range of canopy densities. Agric. Forest Meteorol. 112, 51-56.

Jonckheere, I., Fleck, S., Nackaerts, K., Muys, B., Coppin, P., Weiss, M., Baret, F, 2004. Methods for leaf area index determination. Part I: Theories, techniques and instruments. Agric. Forest Meteorol. 121, 19-35.

Keiser, A.J., Melbourne, S., Rowlinson, D.T., Wall, P.J., 2002. Forest Health Conditions in the Northeast region of Ontario 2001. Regional Report, Great Lake Forestery Centre, Natural Resources Canada. Sault Ste. Marie. 28 pages.

Kucharik, C.J., Norman, J.M., Murdock, L.M., Gower, S.T., 1997. Characterizing canopy nonrandomness with a multiband vegetation imager (MVI). J. Geophys. Res. 102, 29455-29473.

Kucharik, C.J., Norman, J.M., Gower, S.T., 1999. Characterization of radiation regimes in nonrandom forest canopies: theory, measurements, and a simplified modeling approach. Tree Physiol. 19, 695-706.

Lang, A.R.G., Xiang, Y., 1986. Estimation of leaf area index from transmission of direct sunlight in discontinuous canopies. Agric. Forest Meteorol. 35, 229-243.

Leblanc, S.G., 2002. Correction to the plant canopy gap size analysis theory used by the tracing radiation and architecture of canopies (TRAC) instrument. Appl. Optics 31 (36), 7667-7670. 
Leblanc, S.G., 2004. Digital Hemispherical Photography Manual, version 1.0. Canada Centre for Remote Sensing, Natural Resources Canada, Ottawa. 25 pages.

Leblanc, S.G., Chen, J.M., 2000. A windows graphic interface (GUI) for the five-scale model for fast BRDF simulations. Remote Sens. Rev. 19, 293-305.

Leblanc, S.G., Chen, J.M., 2001. A practical scheme for correcting multiple scattering effects on optical LAI measurements. Agric. Forest Meteorol. 110, 125-139.

Leblanc, S.G., Chen, J.M., Kwong, M., 2002. TRAC Manual, version 2.1. Canada Centre for Remote Sensing, Natural Resources Canada, Ottawa. 25 pages.

LI-COR, 1991. LAI-2000 PCA Operating Manual, Li-Cor, Inc., Lincoln, Nebraska.

Miller, J.B., 1967. A Formula for average foliage density. Aust. J. Bot. 15, 141-144.

Miller, E.E., Norman, J.M., 1971. A sunfleck theory for plant canopies. I. length of sunlit segments along a transect. Agron. J. 63, 735-738.

Mizunaga, H., 2000. Prediction of PPFD variance at forest floor in a thinned Japanese cypress plantation. Forest Ecol. Manag.V 126 309-319.

Myneni, R.B., Nemani, R.R., Running, E.W., 1997. Algorithm for the estimation of global land cover, LAI and FPAR based on radiative transfer models. IEEE Trans. Geosci. Remote Sens. 35, 1380-1393.

Neumann, H.H., den Hartog, G., Shaw, R.H., 1989. Leaf area measurements based on hemispheric photographs and leaf-litter collection in a deciduous forest during autumn leaf-fall. Agric. Forest Meteorol. 45, 325-345.

Norman, J.M., Campbell, G.S., 1989. In: Pearcy, R.W., Ehleringer, J.R., Mooney, H.A., Rundel, P.W. (Eds.), Plant Physiological Ecology: Field Methods and Instrumentation. Chapman \& Hall, London, UK, pp. 301-325.

Nilson, T., 1971. A theoretical analysis of the frequency of gaps in plant stands. Agric. Meteorol. 1971 (8), 25-38.

Nilson, T., 1999. Inversion of gap frequency data in forest stands. Agric. Forest Meteorol. 98-99, 437-448.

Olsson, L., Carlsson, K., Grip, H., Perttu, K., 1982. Evaluation of forest-canopy photographs with diode-array scanner OSIRIS. Can. J. Forest Res. 12, 822-828.

Privette, J.L., Myneni, R.B., Knyazikhin, Y., Mukufute, M., Roberts, G., Tian, Y., Wang, Y., Leblanc, S.G., 2002. Early Spatial and Temporal validation of MODIS LAI product in Africa. MODIS special issue of Remote Sens. Environ. 83, 232-243.

Rich, P., 1990. Characterising plant canopies with hemispherical photographs. Remote Sens. Rev. 5 (1), 13-29.
Running, S.W., Nemani, R.R., Peterson, D.L., Band, L.E., Potts, D.F., Pierce, L.L., Spanner, M.A., 1989. Mapping regional forest evapotranspiration and photosynthesis by coupling satellite data with ecosystem simulation. Ecology 70, 1090-1101.

Scurlock, J.M.O., Asner, G.P., Gower, S.T., 2001. Global Leaf Area Index from Field Measurements, 1932-2000. Data set. Available on-line [http://www.daac.ornl.gov] from Oak Ridge National Laboratory Distributed Active Archive Center, Oak Ridge, Tennessee, USA.

Sellers, P.J., Hall, F.G., Kelly, R.D., Black, T.A., Baldocchi, D.B., Berry, J., et al., 1997. BOREAS in 1997: Experiment overview, scientific results and future directions. J. Geophys. Res. 102 (D24), 28731-28769.

Sommer, K., Lang, A., 1994. Comparative analysis of two indirect methods of measuring leaf area index as applied to minimal and spur grape vines. Aust. J. Plant Physiol. 21, 197-206.

Stenberg, P., Kuuluvainen, T., Kellomäki, S., Grace, J., Jokela, E., Gholz, H., 1995. Crown structure, light interception and productivity of pine trees and stands. Ecol. Bull. 43, 20-34.

Van Gardingen, G.E., Jackson, G.E., Hermandez-Daumas, S., Russell, G., Sharp, L., 1999. Leaf area index estimates obtained for clumped canopies using hemispherical photography. Agric. Forest Meteorol. 94, 243-257.

Wagner, S., 1998. Calibration of grey values of hemispherical photographs for image analysis. Agric. Forest Meteorol. 90, 103-117.

Wagner, S., 2001. Relative radiance measurements and zenith angle dependent segmentation in hemispherical photography. Agric. Forest Meteorol. 107, 103-115.

Walter, J.-M., Fournier, R.A., Soudani, K., Meyer, E., 2003. Integrating clumping effects in forest canopy structure: an assessment through hemispherical photographs. Can. J. Remote Sens. 29 (3), 388-410.

Warren-Wilson, J., Reeve, J.E., 1959. Analysis of the spatial distribution of foliage by two-dimensional point quadrats. New Phytol. 58, 92-101.

Weiss, M., Baret, F., Smith, G.J., Jonckheere, I., Coppin, P., 2004. Review of methods for in situ leaf area index (LAI) determination Part II: Estimation of LAI, errors and sampling. Agric. Forest Meteorol. 121, 37-53.

Welles, J.M., Norman, J.M., 1991. Instrument for indirect measurement of canopy architecture. Agron. J. 83, 818-825.

Whitford, K.R., Colquhoun, I.J., Lang, A.R.G., Harper, B.M., 1995. Measuring leaf area index in a sparse eucalypt forest: a comparison of estimate from direct measurement, hemispherical photography, sunlight transmittance, and allometric regression. Agric. Forest Meteorol. 74, 237-249. 